\title{
A New Intelligent Fuzzy Controller for Nonlinear Hysteretic Electronic Throttle in Modern Intelligent Automobiles
}

\author{
Chi-Hsu Wang, Fellow, IEEE, and De-Yu Huang, Member, IEEE
}

\begin{abstract}
In order to control the nonlinear hysteretic electronic throttle adopted in modern automobiles, a new result for the tracking control of nonlinear hysteretic system is first proposed in this paper. Therefore we can realize the intelligent fuzzy logic controller in a well-behaved and systematic manner. A new closed-loop Back-propagation tuning is also proposed for the tuning of the fuzzy output membership functions to yield better tracking result. Finally, the controller synthesis is performed in a real-time environment using $d$ Space MicroAutobox and advanced microcontroller development board to yield excellent tracking results with cost-effective implementation.
\end{abstract}

Index Terms-Electronic throttle (ET), fuzzy logic, hysteretic systems, intelligent control.

\section{INTRODUCTION}

$\mathbf{M}$ ANY OF THE vital functions of today's cars are shifting from a purely mechanical to an electromechanical implementation. These so-called "X-by-wire" systems act as an interface between the driver and the targeted mechanical subsystem of the vehicle (e.g., brakes, throttle valve) [1]-[12]. Coupled with the use of advanced control strategies the "X-bywire" systems can, in general, provide wider functionality and better research and development in vehicle control techniques, such as electric braking control, posture stabilization control, longitudinal control of road vehicles, and electronic throttle (ET) valve control [13]-[15]. ET can replace its mechanical counterpart if a control loop satisfies prescribed requirements, which are a fast transient response without overshoot, positioning within the measurement resolution, and the control action that does not wear out the components [3]. These high-quality controldemands are difficult to accomplish since the throttle is burdened with strong nonlinear hysteretic effects of friction and return spring [3], [16], [17]. Moreover, the control strategy should be simple enough to be implemented on a low-cost

Manuscript received November 1, 2011; revised January 20, 2012 and March 1, 2012; accepted March 28, 2012. Date of publication May 3, 2012; date of current version February 6, 2013. This work was supported by the National Science Council, Taiwan, under the title of "Design and Implementation of Intelligent Controller for Electronic Throttle of Advanced Vehicles," 100-2221E-009-027-, $2011 \sim 2012$.

C.-H. Wang is with the National Chiao-Tung University, Department of Electrical engineering, Hsihchu 300, Taiwan (e-mail: cwang@cn.nctu.edu.tw).

D.-Y. Huang is with the Department of Electrical engineering, Institute of Electrical control engineering, National Chiao-Tung University, Hsihchu 300, Taiwan (e-mail: u8302230bodyownn@yahoo.com.tw).

Color versions of one or more of the figures in this paper are available online at http://ieeexplore.iee.org.

Digital Object Identifier 10.1109/TIE.2012.2193861 automotive microcontroller system, while it has to be robust to plant parameter variations.

Recently, several control strategies for ET have been presented; differing in the underlying philosophy and complexity [3], [18]-[34]. However, these ET control (ETC) systems have their weak points in practical applications. In [17], the nonlinear hysteretic ET was also discussed and controlled by variable structure (VS) controller via the expensive dSpace DSP boards [35]. This kind of expensive laboratory implementation is still questionable in real industrial cost-effective implementations. Furthermore, its performance still has chattering effects due to the nature of VS controller under high gain.

The principal aim of this paper is to present a new intelligent controller for nonlinear hysteretic ET. Several new properties for the control of nonlinear hysteretic system (NHS) will be explored in this paper, which will lead to the design of a stable fuzzy logic controller for the tracking of drivers' pedal signals [36], [37]. Under the proposed feedforward configuration for tracking control, a new theorem is developed to show the existence with special properties of a stable controller (of any kind) for the NHS. These special properties will allow us to realize the stable intelligent fuzzy controller in a well-behaved and systematic manner. To improve the tracking performance, a new closed-loop Back-propagation tuning is also proposed for the tuning of the fuzzy output membership functions to yield better tracking result. We adopt the ET of SAAB-91-88186, which have been used in Saab 95 from 1998 [34]. The MicroAutobox (MABX) [35] from dSPACE will mainly be adopted for the identification of the hysteretic loop in ET. The expensive MABX can also be used for the real-time control of ET with good confidence. For comparison, the PID-tuned controller is also designed by using Matlab Toolbox [38] and realized using MABX. However, for real industrial applications, we adopt the cost-effective advanced microcontroller to implement the real-time FLC by converting the floating point numbers to fix point integers. The final FLC is also realized in look-up table stored in the microcontroller for fast realtime operations. Excellent tracking results are obtained using the cost-effective microcontroller, which is even better than the PID-tuned controller in MABX under our new development.

\section{Nonlinear Hysteretic Electronic THROTTLE USING BLDC (ET-BLDC)}

The ET in modern automobiles is usually a brushless dc (BLDC) motor with $12 \mathrm{~V} / 5 \mathrm{~A}$ rating. It is also a strong nonlinear 


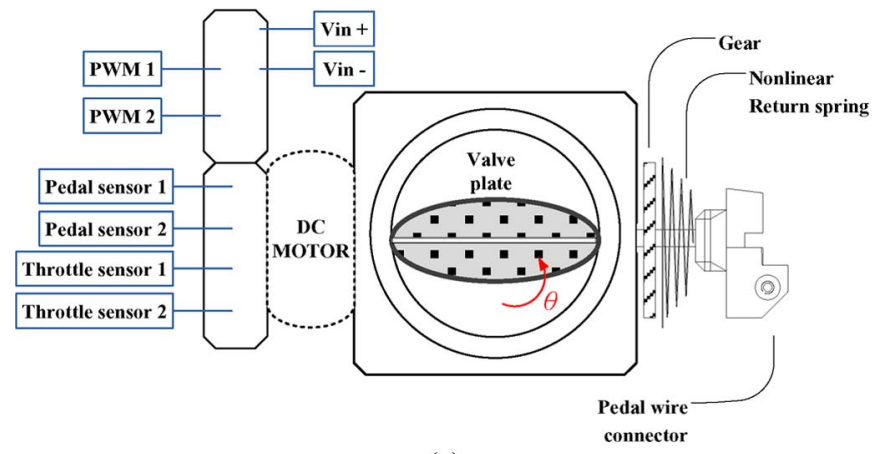

(a)

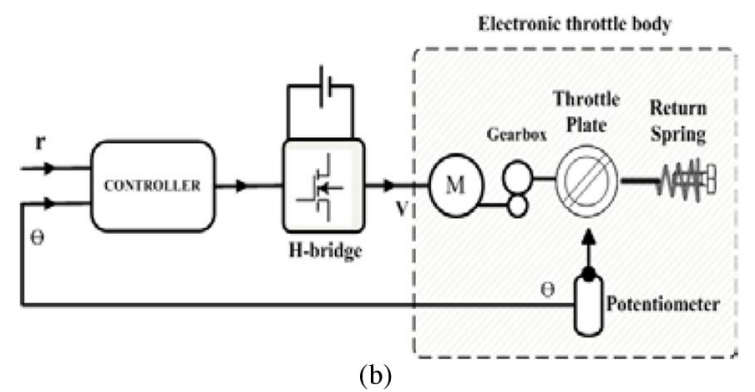

Fig. 1. (a) The nonlinear electronic throttle. (b) The electronic throttle with controller

device with hysteretic phenomenon, friction, and return spring nonlinearities, as shown in the following Fig. 1(a). The dotted block in Fig. 1(b) shows the schematic diagram for ET body. The H-bridge is the power amplifier to boost the power of the control output from the electronic controller.

The nonlinear ET has four sensors, including two pedal sensors and two throttle sensors. When the driver pushes or relaxes the pedal to vary the speed, ET's pedal sensors will receive the signals in the same time. The throttle valve is controlled by a brushless throttle motor with a $600-\mathrm{Hz}$ pulse width modulation (PWM) signal.

\section{Nonlinear HySteretic SyStem (NHS)}

The throttle is a valve used in vehicles to regulate air inflow into the engine combustion system. The air throughput is controlled by the opening angle of the valve plate in the air tube. Traditionally, the throttle valve plate was directly connected to the gas pedal by a mechanical cable. The reason is that the amount of air inflow is proportional to the desired engine speed, which is decided by the position of the gas pedal. Nowadays, however, the throttle cable has been substituted with the throttle-by-wire system since around 1998. The throttle-by-wire system consists of a dc motor with computer controller to convert the position of the gas pedal to the angle of throttle valve position. The gas pedal sensor provides the driver command to a throttle control module (TCM) in Engine Management System which then specifies proper airfuel mixture to be fed into the engine. In particular, the TCM finds a proper control output that positions the throttle valve in the desired opening angle, the ETC system. Fig. 2 shows a typical illustration of hysteretic phenomenon. Hysteretic phenomena occur in magnetic materials, ferromagnetic materials, and ferroelectric materials, as well as in the elastic, electric, and magnetic behavior of materials, in which a lag occurs between

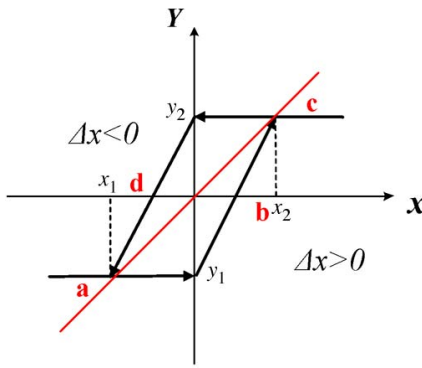

(a)

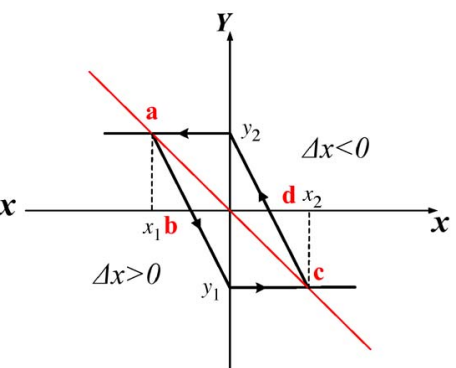

(b)
Fig. 2. Nonlinear hysteretic system.

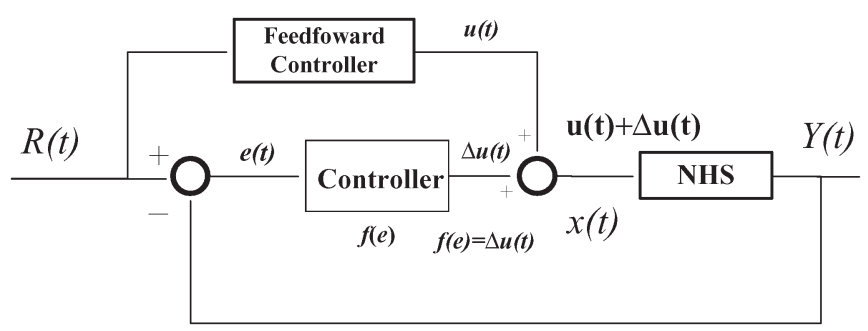

Fig. 3. Control strategy to control the NHS.

the application and the removal of a force. Electric hysteretic occurs when applying a varying electric field and elastic hysteretic occurs in response to a varying force, such as the dc brushless motor in ET adopted in this paper. The hysteretic is often used specifically to represent rate-independent state. The magnetized iron or the thermostat has this property. In the paper, the ET is a NHS with rate dependency, and its property is shown in Fig. 2. The NHS shown in Fig. 2 is input/output bounded, i.e., $x_{1} \leq x(t) \leq x_{2}$ and $y_{1} \leq y(t) \leq y_{2}$. In Fig. 2, when the input force $x(t)$ increases, i.e., $\Delta x(t)>0$, the ET will operate from close to open, which is $a \rightarrow b \rightarrow c$ in Fig. 2. When $x(t)$ decreases, i.e., $\Delta x(t)<0$, the ET will operate from open to close, which is $c \rightarrow d \rightarrow a$ in Fig. 2 . Note that although we have two cases of NHS in Fig. 2, all the discussions in this paper will be applied equally. For simplicity, the NHS in Fig. 2(a) will be adopted for illustrations in the remaining of this paper.

\section{Stable Control Strategy for NHS}

To properly control the nonlinear dc brushless motor with hysteretic phenomenon, we propose the following feedforward closed-loop configuration.

In Fig. 3, the $R(t)$ is input signal to the system and the feedforward controller will decide a nominal output command $u(t)$ based on $R(t)$ to steer the NHS. The feedforward controller is actually a transducer to convert the physical $R(t)$ signal into the electrical signal $u(t)$. For instance, the $R(t)$ can be the mechanical pedal signal by the automobile driver, the $u(t)$ will be the equivalent electrical signal generated by the transducer. The $e(t)$ and $\Delta e(t)$ between $R(t)$ and $Y(t)$ will be the inputs to the controller. The controller will then generate a $\Delta u(t)$ to be added with the nominal control command $u(t)$ to the NHS. It is hoped that the controller will generate a proper $\Delta u(t)$ to compensate the nominal command $u(t)$ to steer the NHS to the desired $Y(t)$.

To better illustrate the control strategy for the controller to generate $\Delta u(t)$, we have the following arrangements. In Fig. 4, 


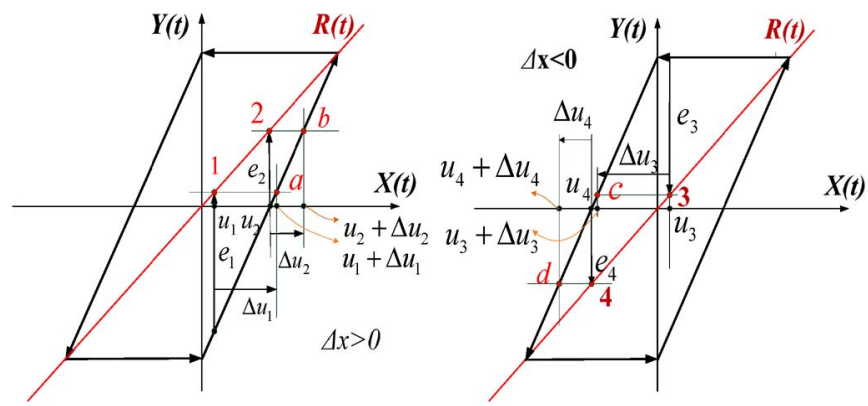

Fig. 4. Control strategy of the hysteretic loop when $\Delta x(t)>0$ and $\Delta x(t)<0$.
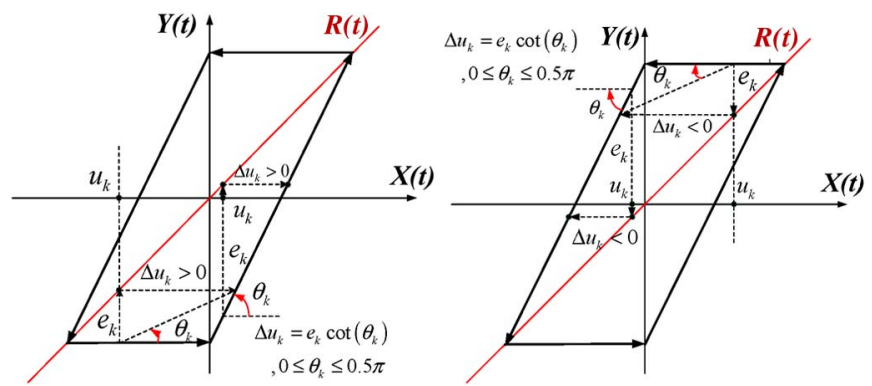

Fig. 5. Relationship between $e$ and $\Delta u(=f(e))$.

when $\Delta x(t)>0$, the output $Y(t)$ will follow the direction pointed by the arrows if $\Delta u=0$. However, the goal is to let $Y(t)$ to track $R(t)$, so we need to generate a proper nonzero $\Delta u$ to let $Y(t)$ follow $R(t)$. When $x(t)=u_{1}(t)$, the error is $e_{1}(t)>0$. By drawing a horizontal line across point 1 to intersect the hysteretic loop at point a in Fig. 4, we have the desired $\Delta u_{1}$ to let $x(t)=u_{1}(t)+\Delta u_{1}(t)$, so that $Y(t)$ will be equal to $R(t)$ at that moment. In this case, $\Delta u_{1}(t)$ is positive. Similarly, when $x(t)=u_{2}(t)$, the error is $e_{2}(t)>0$. By drawing a horizontal line across point 2 to intersect the hysteretic loop at point b in Fig. 4, we have the desired $\Delta u_{2}$ to let $x(t)=u_{2}(t)+\Delta u_{2}(t)$. In this case, $\Delta u_{2}(t)$ is also positive. In fact, we can say that $e f(e)=e \Delta u>0$ when $\Delta x(t)>0$. Similar discussions can be made at points 3 to $\mathrm{c}$ and 4 to $\mathrm{d}$ in Fig. 4 for $\Delta x(t)<0$. This will yield $e<0$ and $\Delta u<0$ to have $e f(e)=e \Delta u>0$. It is also obvious from Fig. 4 that if $e=0$ will imply $\Delta u=f(\boldsymbol{e})=0$.

Furthermore, Fig. 5 shows the relationship between $e$ and $\Delta u$ by

$$
\Delta u=f(e)=e \cot (\theta), \quad 0<\theta \leq \cot ^{-1}\left(\frac{2 m}{n}\right)<\frac{\pi}{2} .
$$

To facilitate the proofs of the following theorems, the following Fig. 6 provides a general presentation for the hysteretic loop, where all $\boldsymbol{n}_{1}, \boldsymbol{n}_{2}, \boldsymbol{n}_{3}$, and $\boldsymbol{m}$ are greater than zero.

It is desired for output $y(t)$ to track $R(t)$ whose equation is in the following form:

$$
R(t)=\frac{m}{n_{1}} x
$$

The right-hand-side (RHS) loop $(\Delta x>0)$ in Fig. 6 is

$$
\left\{\begin{array}{ll}
y=\frac{2 m}{n_{1}+n_{2}} x+\frac{m\left(n_{2}-n_{1}\right)}{n_{1}+n_{2}}, & \text { if }-n_{2} \leq x \leq n_{1} \\
y=-m, & \text { if }-n_{1} \leq x<-n_{2}
\end{array} .\right.
$$

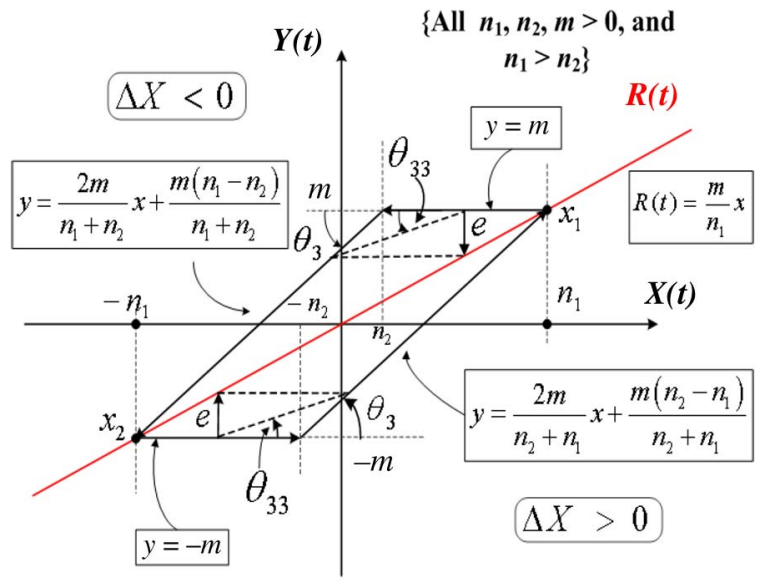

Fig. 6. Hysteretic loop when $\Delta x>0$ and $\Delta x<0$.

The left-hand-side (LHS) loop $(\Delta x<0)$ in Fig. 6 is

$$
\left\{\begin{array}{ll}
y=m, & \text { if } n_{2}<x \leq n_{1} \\
y=\frac{2 m}{n_{1}+n_{2}} x+\frac{m\left(n_{1}-n_{2}\right)}{n_{1}+n_{2}}, & \text { if }-n_{1} \leq x \leq n_{2}
\end{array} .\right.
$$

As previously mentioned that the feedforward controller is only a transducer to convert the physical signal $\mathrm{R}(\mathrm{t})$ into the electrical signal $u(t)$, we let

$$
u(t)=\alpha R(t) .
$$

Therefore,

$$
e(t)=R(t)-N H S(u(t)+\Delta u(t)) .
$$

Because the hysteretic loop is a nonlinear and multiple valued function with different outputs according to the sign of $\Delta x$, i.e., $\Delta x>0$ and $\Delta x<0$. When $\Delta x>0$, the $y(t)$ will follow the RHS hysteretic loop to produce $e(t)$ and $\Delta u(t)$. We also define

$$
\cot \theta_{3}=\frac{n_{1}+n_{2}}{2 m} \text { and } \cot \theta_{33}=\frac{\left(n_{2}-n_{1}\right)\left(|x|+n_{1}\right)}{2 m\left(|x|-n_{1}\right)},
$$

when $\Delta x>0$ and $\Delta x<0$.

It is obvious that $\cot \theta_{3}>0, \cot \theta_{33}>0$ due to the fact that $\left\{n_{1}, n_{2}, m>0\right.$, and $\left.n_{1}>n_{2}\right\}$. The following Theorem 1 will prove the above discussions in a formal way.

Theorem 1: For the closed-loop configuration in Fig. 3 with its controller output $\Delta u$ defined in Fig. 4 to control the NHS, if and only if the closed-loop system in Fig. 3 is asymptotically stable i.e., $\lim _{t \rightarrow \infty} e(t)=0$, then

$$
\text { ef }(e)=e \Delta u \geq 0 \text {, with }
$$

$$
\Delta u=f(e)=\left\{\begin{array}{c}
\frac{n_{2}-n_{1}}{2 n_{1}}\left[x(t)-n_{1}\right]=e(t) \cot \theta^{*}, \\
\text { if } \Delta x \geq 0 \text { and } \theta^{*} \text { is } \theta_{3} \text { or } \theta_{33} \\
\frac{n_{2}-n_{1}}{2 n_{1}}\left[x(t)+n_{1}\right]=e(t) \cot \theta^{*}, \\
\text { if } \Delta x \leq 0 \text { and } \theta^{*} \text { is } \theta_{3} \text { or } \theta_{33}
\end{array} .\right.
$$


Proof: Part A: We will show that if the system is asymptotically stable then

$$
\begin{aligned}
e f(e)=e \Delta u \geq 0, \text { with } \\
\qquad u=f(e)=\left\{\begin{array}{l}
\frac{n_{2}-n_{1}}{2 n_{1}}\left[x(t)-n_{1}\right]=e(t) \cot \theta^{*}, \\
\text { if } \Delta x \geq 0 \text { and } \theta^{*} \text { is } \theta_{3} \text { or } \theta_{33} \\
\frac{n_{2}-n_{1}}{2 n_{1}}\left[x(t)+n_{1}\right]=e(t) \cot \theta^{*}, \\
\text { if } \Delta x \leq 0 \text { and } \theta^{*} \text { is } \theta_{3} \text { or } \theta_{33}
\end{array}\right.
\end{aligned}
$$

When $\boldsymbol{\Delta} \boldsymbol{x}>0$, we can have two cases, i.e., $-n_{2} \leq x \leq n_{1}$ and $-n_{1} \leq x \leq-n_{2}$.

1) When $-n_{2} \leq x \leq n_{1}$, the error signal $\boldsymbol{e}(t)$ without control $\Delta u(t)$ at time $t$ is

$$
e(t)=R(t)-Y(t)=\frac{m\left(n_{2}-n_{1}\right)}{n_{1}\left(n_{2}+n_{1}\right)}\left[x(t)-n_{1}\right] \geq 0 .
$$

In Fig. 6, we can see the error $\boldsymbol{e}(t)$ and then find out the $\Delta u(t)$. However, the proper $\Delta u(t)$ will be added in the next time instant $t \approx t+\Delta t$, which follows closely from the control principle shown in Fig. 4, so that the system will be asymptotically stable. Since the system is assumed to be asymptotically stable, we can have

$$
\begin{array}{r}
\lim _{t \rightarrow \infty} e(t)=\lim _{t \rightarrow \infty}\left\{\frac{m}{n_{1}} x(t)-\left[\frac{2 m}{n_{1}+n_{2}}(x(t)+\Delta u(t))\right.\right. \\
\left.\left.+\frac{m\left(n_{2}-n_{1}\right)}{\left(n_{2}+n_{1}\right)}\right]\right\}
\end{array}
$$$$
=0 \text {. }
$$

This will let us find the approximate $\Delta u(t)$ in finite time $t$. Therefore, the proper $\Delta u(t)$ can be found as

$$
\begin{aligned}
\Delta u(t) & =\frac{n_{2}-n_{1}}{2 n_{1}}\left[x(t)-n_{1}\right] \\
& =\frac{m\left(n_{2}-n_{1}\right)}{n_{1}\left(n_{2}+n_{1}\right)}\left[x(t)-n_{1}\right] * \frac{\left(n_{2}+n_{1}\right)}{2 m} \\
& =e(t) * \cot \theta_{3} \geq 0 .
\end{aligned}
$$

Therefore, $\quad e(t) * f(e(t))=e(t) * \Delta u(t) \geq 0 \quad$ with $\Delta u(t)$ shown in (9). Further, if $\boldsymbol{e}(t)=0$, then $x(t)=n_{1}$, therefore $\Delta u(t)=f(\boldsymbol{e}(t))=f(0)=0$.

2) When $-n_{1} \leq x \leq-n_{2}$, the error signal $e(t)$ without control $\Delta u(t)$ at time $t$ is

$$
e(t)=R(t)-Y(t)=\frac{m}{n_{1}}\left[x(t)+n_{1}\right] \geq 0 .
$$

In Fig. 6, we can see the error $e(t)$ and then find out the $\Delta u(t)$. However, the proper $\Delta u(t)$ will be added in the next time instant $t \approx t+\Delta t$, which follows closely from the control principle shown in Fig. 4, so that the system will be asymptotically stable. Since the system is assumed to be asymptotically stable, we can have

$$
\begin{array}{r}
\lim _{t \rightarrow \infty} e(t)=\lim _{t \rightarrow \infty}\left\{\frac{m}{n_{1}} x(t)-\left[\frac{2 m}{n_{1}+n_{2}}(x(t)+\Delta u(t))\right.\right. \\
\left.\left.+\frac{m\left(n_{2}-n_{1}\right)}{\left(n_{2}+n_{1}\right)}\right]\right\}
\end{array}
$$$$
=0 \text {. }
$$

This will let us find the approximate $\Delta u(t)$ in finite time $t$. Therefore, the proper $\Delta u(t)$ can be found as

$$
\begin{aligned}
\Delta u(t) & =\frac{n_{2}-n_{1}}{2 n_{1}}\left[x(t)-n_{1}\right] \\
& =\frac{m}{n_{1}}\left[x(t)+n_{1}\right] * \frac{\left(n_{2}-n_{1}\right)\left(|x|+n_{1}\right)}{2 m\left(|x|-n_{1}\right)} \\
& =e(t) * \cot \theta_{33} \geq 0 .
\end{aligned}
$$

Therefore, $\quad e(t) * f(e(t))=e(t) * \Delta u(t) \geq 0 \quad$ with $\Delta u(t)$ shown in (12). Further, if $e(t)=0$, then $x(t)=-n_{1}$, therefore $\Delta u(t)=f(\boldsymbol{e}(t))=f(0)=0$. It is obvious that $\Delta u(t)$ defined in (9) and (12) are identical for $\Delta x>0$.

When $\boldsymbol{\Delta} \boldsymbol{x}<0$, the $y(t)$ will follow the LHS hysteretic loop, and it produces $e(t)$ and $\Delta u(t)$ in Fig. 6. When $\Delta x<0$, we can also have two cases, i.e., $-n_{1} \leq x \leq n_{2}$ and $n_{2} \leq x \leq n_{1}$.

1) When $-n_{1} \leq x \leq n_{2}$, the error signal $e(t)$ without control $\Delta u(t)$ at time $t$ is

$$
e(t)=R(t)-Y(t)=\frac{m\left(n_{2}-n_{1}\right)}{n_{1}\left(n_{2}+n_{1}\right)}\left[x(t)+n_{1}\right] \leq 0 .
$$

In Fig. 6, we can see the error $e(t)$ and then find out the $\Delta u(t)$. However, the proper $\Delta u(t)$ will be added in the next time instant $t \approx t+\Delta t$, which follows closely from the control principle shown in Fig. 3, so that the system will be asymptotically stable. Since the system is assumed to be asymptotically stable, we can have

$$
\begin{aligned}
\lim _{t \rightarrow \infty} e(t)=\lim _{t \rightarrow \infty}\left\{\frac{m}{n_{1}} x(t)-\left[\frac{2 m}{n_{1}+n_{2}}(x(t)+\Delta u(t))\right.\right. \\
\left.\left.\quad+\frac{m\left(n_{2}-n_{1}\right)}{\left(n_{2}+n_{1}\right)}\right]\right\} \\
=0 .
\end{aligned}
$$

This will let us find the approximate $\Delta u(t)$ in finite time $t$. Therefore, the proper $\Delta u(t)$ can be found as

$$
\begin{aligned}
\Delta u(t) & =\frac{\left(n_{2}-n_{1}\right)}{2 n_{1}}\left(x(t)+n_{1}\right) \\
& =\frac{m\left(n_{2}-n_{1}\right)}{n_{1}\left(n_{2}+n_{1}\right)}\left[x(t)+n_{1}\right] * \frac{n_{1}+n_{2}}{2 m} \\
& =e(t) * \cot \theta_{3} \leq 0 .
\end{aligned}
$$

Therefore, $\quad e(t) * f(e(t))=e(t) * \Delta u(t) \geq 0 \quad$ with $\Delta u(t)$ shown in (15). Further, if $\boldsymbol{e}(t)=0$, then $x(t)=-n_{1}$, therefore $\Delta u(t)=f(\boldsymbol{e}(t))=f(0)=0$.

2) When $n_{2} \leq x \leq n_{1}$, the error signal $\boldsymbol{e}(t)$ without control $\Delta u(t)$ at time $t$ is

$$
e(t)=R(t)-Y(t)=\frac{m}{n_{1}}\left[x(t)-n_{1}\right] \leq 0 .
$$

In Fig. 6, we can see the error $e(t)$ and then find out the $\Delta u(t)$. However, the proper $\Delta u(t)$ will be added in the next time instant $t \approx t+\Delta t$, which follows closely from the control principle shown in Fig. 4, so that the 
system will be asymptotically stable. Since the system is assumed to be asymptotically stable, we can have

$$
\begin{aligned}
\lim _{t \rightarrow \infty} e(t)=\lim _{t \rightarrow \infty}\left\{\frac{m}{n_{1}} x(t)-\left[\frac{2 m}{n_{1}+n_{2}}(x(t)+\Delta u(t))\right.\right. \\
\left.\left.+\frac{m\left(n_{2}-n_{1}\right)}{\left(n_{2}+n_{1}\right)}\right]\right\} \\
=0 .
\end{aligned}
$$

This will let us find the approximate $\Delta u(t)$ in finite time $t$. Therefore, the proper $\Delta u(t)$ can be found as

$$
\begin{aligned}
\Delta u(t) & =\frac{\left(n_{2}-n_{1}\right)}{2 n_{1}}\left(x(t)+n_{1}\right) \\
& =\frac{m}{n_{1}}\left[x(t)-n_{1}\right] * \frac{\left(n_{2}-n_{1}\right)\left(|x|+n_{1}\right)}{2 m\left(|x|-n_{1}\right)} \\
& =e(t) * \cot \theta_{33} \leq 0 .
\end{aligned}
$$

Therefore, $\quad e(t) * f(e(t))=e(t) * \Delta u(t) \geq 0 \quad$ with $\Delta u(t)$ shown in (17). Further, if $\boldsymbol{e}(t)=0$, then $x(t)=n_{1}$, therefore $\Delta u(t)=f(\boldsymbol{e}(t))=f(0)=0$. It is obvious that $\Delta u(t)$ defined in (15) and (17) are identical for $\Delta x<0$.

Part B: We will show that if the system has error $e(t)$ and

$$
\begin{aligned}
\text { ef }(e)=e \Delta u \geq & 0, \text { with } \\
\qquad u & =f(e)=\left\{\begin{array}{c}
\frac{n_{2}-n_{1}}{2 n_{1}}\left[x(t)-n_{1}\right]=e(t) \cot \theta^{*}, \\
\text { if } \Delta x \geq 0 \text { and } \theta^{*} \text { is } \theta_{3} \text { or } \theta_{33} \\
\frac{n_{2}-n_{1}}{2 n_{1}}\left[x(t)+n_{1}\right]=e(t) \cot \theta^{*}, \\
\text { if } \Delta x \leq 0 \text { and } \theta^{*} \text { is } \theta_{3} \text { or } \theta_{33}
\end{array}\right.
\end{aligned}
$$

then it is asymptotically stable. When $\Delta x>0$, we can have two cases, i.e., $-n_{2} \leq x \leq n_{1}$ and $-n_{1} \leq x \leq-n_{2}$.

1) When $-n_{2} \leq x \leq n_{1}$, the error signal $e(t)$ without control $\Delta u(t)$ at time $t$ is

$$
e(t)=R(t)-Y(t)=\frac{m\left(n_{2}-n_{1}\right)}{n_{1}\left(n_{2}+n_{1}\right)}\left[x(t)-n_{1}\right] \geq 0 .
$$

In Fig. 6, we can see the error $e(t)$ and then find out the $\Delta u(t)$. However, the proper $\Delta u(t)$ will be added in the next time instant $t \approx t+\Delta t$, which follows closely from the control principle shown in Fig. 4. We can have the approximate $\Delta u(t)$ in finite time $t$

$$
\begin{aligned}
\Delta u(t) & =\frac{n_{1}+n_{2}}{2 m}\left[y(t)-\frac{m\left(n_{2}-n_{1}\right)}{\left(n_{2}+n_{1}\right)}\right]-\frac{n_{1}}{m} y(t) \\
& =\frac{n_{2}-n_{1}}{2 n_{1}}\left[x(t)-n_{1}\right] .
\end{aligned}
$$

The $\Delta u(t)$ can be rewritten as

$$
\begin{aligned}
\Delta u(t)= & \frac{n_{2}-n_{1}}{2 n_{1}}\left[x(t)-n_{1}\right]=\frac{m\left(n_{2}-n_{1}\right)}{n_{1}\left(n_{2}+n_{1}\right)}\left[x(t)-n_{1}\right] \\
& * \frac{\left(n_{2}+n_{1}\right)}{2 m} \\
= & e(t) * \cot \theta_{3} \geq 0 .
\end{aligned}
$$

Therefore, $\quad e(t) * f(e(t))=e(t) * \Delta u(t) \geq 0$. Further, if $\boldsymbol{e}(t)=0$, then $x(t)=n_{1}$, therefore $\Delta u(t)=f(\boldsymbol{e}(t))=f(0)=0$.
Then, we consider the error $e(t)$ with $\Delta u(t)$, the error can be found as

$$
\begin{aligned}
& \lim _{t \rightarrow \infty} e(t)= \lim _{t \rightarrow \infty}(R(t)-y(t)) \\
&=\lim _{t \rightarrow \infty}\left\{\frac{m}{n_{1}} x(t)-\left[\frac{2 m}{n_{2}+n_{1}}(x(t)+\Delta u(t))\right.\right. \\
&\left.\left.\quad+\frac{m\left(n_{2}-n_{1}\right)}{n_{2}+n_{1}}\right]\right\}
\end{aligned}
$$$$
=0 \text {. }
$$

The error will be decreased to zero as time goes to infinity, and the system will be asymptotically stable.

2) When $-n_{1} \leq x \leq-n_{2}$, the error signal $\boldsymbol{e}(t)$ without control $\Delta u(t)$ at time $t$ is

$e(t)=\frac{m}{n_{1}} x(t)-(-m)=\frac{m}{n_{1}}\left[x(t)+n_{1}\right] \geq 0$.

In Fig. 6, we can see the error $\boldsymbol{e}(t)$ and then find out the $\Delta u(t)$. However, the proper $\Delta u(t)$ will be added in the next time instant $t \approx t+\Delta t$, which follows closely from the control principle shown in Fig. 4. We can have the approximate $\Delta u(t)$ in finite time $t$

$$
\begin{aligned}
\Delta u(t) & =\frac{n_{1}+n_{2}}{2 m}\left[y(t)-\frac{m\left(n_{2}-n_{1}\right)}{\left(n_{2}+n_{1}\right)}\right]-\frac{n_{1}}{m} y(t) \\
& =\frac{n_{2}-n_{1}}{2 n_{1}}\left[x(t)-n_{1}\right] .
\end{aligned}
$$

The $\Delta u(t)$ can be rewritten as

$$
\begin{aligned}
\Delta u(t)= & \frac{n_{2}-n_{1}}{2 n_{1}}\left[x(t)-n_{1}\right]=\frac{m}{n_{1}}\left[x(t)+n_{1}\right] \\
& * \frac{\left(n_{2}-n_{1}\right)\left(x-n_{1}\right)}{2 m\left(x+n_{1}\right)} \\
= & e(t) * \cot \theta_{33} \geq 0 .
\end{aligned}
$$

Therefore, $e(t) * f(e(t))=e(t) * \Delta u(t) \geq 0$. Further, if $\boldsymbol{e}(t)=0$, then $x(t)=-n_{1}$, therefore $\Delta u(t)=$ $f(\boldsymbol{e}(t))=f(0)=0$. Then, we consider the error $\boldsymbol{e}(t)$ with $\Delta u(t)$, the error can be found as

$$
\begin{aligned}
& \lim _{t \rightarrow \infty} e(t)= \lim _{t \rightarrow \infty}(R(t)-y(t)) \\
&=\lim _{t \rightarrow \infty}\left\{\frac{m}{n_{1}} x(t)-\left[\frac{2 m}{n_{2}+n_{1}}(x(t)+\Delta u(t))\right.\right. \\
&\left.\left.\quad+\frac{m\left(n_{2}-n_{1}\right)}{n_{2}+n_{1}}\right]\right\} \\
&=0 .
\end{aligned}
$$

The error will be decreased to zero as time goes to infinity, and the system will be asymptotically stable.

When $\Delta x<0$, the $y(t)$ will follow the LHS hysteretic loop and it produces $e(t)$ and $\Delta u(t)$ in Fig. 6. When $\Delta x<0$, we can also have two cases, i.e., $-n_{1} \leq x \leq n_{2}$ and $n_{2} \leq x \leq n_{1}$. 
I. When $-n_{1} \leq x \leq n_{2}$, the error signal $e(t)$ without control $\Delta u(t)$ at time $t$ is

$$
\begin{aligned}
e(t) & =\frac{m}{n_{1}} x(t)-\left[\frac{2 m}{n_{1}+n_{2}} x(t)+\frac{m\left(n_{1}-n_{2}\right)}{n_{1}+n_{2}}\right] \\
& =\frac{m\left(n_{2}-n_{1}\right)}{n_{1}\left(n_{2}+n_{1}\right)}\left[x(t)+n_{1}\right] \leq 0 .
\end{aligned}
$$

In Fig. 6, we can see the error $\boldsymbol{e}(t)$ and then find out the $\Delta u(t)$. However, the proper $\Delta u(t)$ will be added in the next time instant $t \approx t+\Delta t$, which follows closely from the control principle shown in Fig. 4. We can have the approximate $\Delta u(t)$ in finite time $t$

$$
\begin{aligned}
\Delta u(t) & =\frac{n_{2}-n_{1}}{2 m}\left[y(t)-\frac{m\left(n_{1}-n_{2}\right)}{n_{1}+n_{2}}\right]-\frac{n_{1}}{m} y(t) \\
& =\frac{\left(n_{2}-n_{1}\right)}{2 n_{1}}\left(x(t)+n_{1}\right) .
\end{aligned}
$$

The $\Delta u(t)$ can be rewritten as

$$
\begin{aligned}
\Delta u(t)= & \frac{\left(n_{2}-n_{1}\right)}{2 n_{1}}\left(x(t)+n_{1}\right)=\frac{m\left(n_{2}-n_{1}\right)}{n_{1}\left(n_{2}+n_{1}\right)}\left[x(t)+n_{1}\right] \\
& * \frac{n_{1}+n_{2}}{2 m} \\
= & e(t) * \cot \theta_{3} \leq 0 .
\end{aligned}
$$

Therefore, $\quad e(t) * f(e(t))=e(t) * \Delta u(t) \geq 0$. Further, if $\boldsymbol{e}(t)=0$, then $x(t)=-n_{1}$, therefore $\Delta u(t)=f(\boldsymbol{e}(t))=f(0)=0 . \quad$ Then, we consider the error $e(t)$ with $\Delta u(t)$, the error can be found as

$$
\begin{aligned}
& \lim _{t \rightarrow \infty} e(t)= \lim _{t \rightarrow \infty}(R(t)-y(t)) \\
&=\lim _{t \rightarrow \infty}\left\{\frac{m}{n_{1}} x(t)-\left[\frac{2 m}{n_{2}+n_{1}}(x(t)+\Delta u(t))\right.\right. \\
&\left.\left.\quad+\frac{m\left(n_{1}-n_{2}\right)}{n_{1}+n_{2}}\right]\right\}
\end{aligned}
$$$$
=0 \text {. }
$$

The error will be decreased to zero as time goes to infinity and the system will be asymptotically stable.

II. When $n_{2} \leq x \leq n_{1}$, the error signal $e(t)$ without control $\Delta u(t)$ at time $t$ is

$$
e(t)=\frac{m}{n_{1}} x(t)-m=\frac{m}{n_{1}}\left[x(t)-n_{1}\right] \leq 0 .
$$

In Fig. 6, we can see the error $e(t)$ and then find out the $\Delta u(t)$. However, the proper $\Delta u(t)$ will be added in the next time instant $t \approx t+\Delta t$, which follows closely from the control principle shown in Fig. 4. We can have the approximate $\Delta u(t)$ in finite time $t$

$$
\begin{aligned}
\Delta u(t) & =\frac{n_{2}+n_{1}}{2 m}\left[y(t)-\frac{m\left(n_{1}-n_{2}\right)}{n_{1}+n_{2}}\right]-\frac{n_{1}}{m} y(t) \\
& =\frac{\left(n_{2}-n_{1}\right)}{2 n_{1}}\left(x(t)+n_{1}\right) .
\end{aligned}
$$

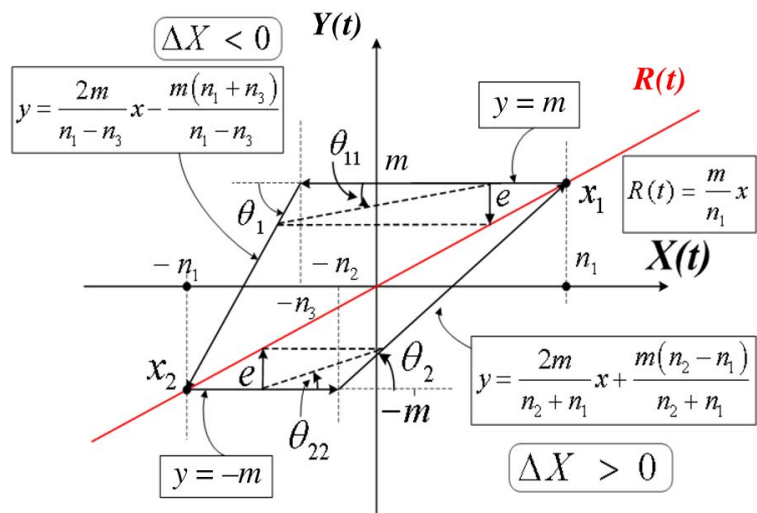

Fig. 7. Hysteretic loop when $\Delta x(t)>0$ and $\Delta x(t)<0$.

The $\Delta u(t)$ can be rewritten as

$$
\begin{aligned}
\Delta u(t)= & \frac{\left(n_{2}-n_{1}\right)}{2 n_{1}}\left(x(t)+n_{1}\right)=\frac{m}{n_{1}}\left[x(t)-n_{1}\right] \\
& * \frac{\left(n_{2}-n_{1}\right)\left(|x|+n_{1}\right)}{2 m\left(|x|-n_{1}\right)} \\
= & e(t) * \cot \theta_{33} \leq 0 .
\end{aligned}
$$

Therefore, $e(t) * f(e(t))=e(t) * \Delta u(t) \geq 0$. Further, if $\boldsymbol{e}(t)=0$, then $x(t)=n_{1}$, therefore $\Delta u(t)=f(\boldsymbol{e}(t))=$ $f(0)=0$. Then, we consider the error $e(t)$ with $\Delta u(t)$, the error can be found as

$$
\begin{aligned}
\lim _{t \rightarrow \infty} e(t) & =\lim _{t \rightarrow \infty}(R(t)-y(t)) \\
= & \lim _{t \rightarrow \infty}\left\{\frac{m}{n_{1}} x(t)-\left[\frac{2 m}{n_{2}+n_{1}}(x(t)+\Delta u(t))\right.\right. \\
& \left.\left.\quad+\frac{m\left(n_{1}-n_{2}\right)}{n_{1}+n_{2}}\right]\right\} \\
= & 0 .
\end{aligned}
$$

The error will be decreased to zero as time goes to infinity, and the system will be asymptotically stable. Q.E.D.

When the NHS is not symmetrical, as shown in the following Fig. 7, we still have the following similar results, where $\boldsymbol{n}_{1}, \boldsymbol{n}_{2}$, $n_{3}$, and $m$ are all assumed to be greater to the zero. The proof of Theorem 2 is skipped for simplicity.

Theorem 2: For the closed-loop configuration in Fig. 2 with its controller output $\Delta u$ defined in Fig. 7 to control the NHS, if and only if the closed-loop system in Fig. 3 is asymptotically stable, i.e., $\lim _{t \rightarrow \infty} e(t)=0$, then

$$
\begin{aligned}
e f(e)=e \Delta u \geq 0, \text { with } \\
\qquad u=f(e)=\left\{\begin{array}{l}
\frac{n_{2}-n_{1}}{2 n_{1}}\left[x(t)-n_{1}\right]=e(t) \cot \theta^{*}, \\
\text { if } \Delta x \geq 0 \text { and } \theta^{*} \text { is } \theta_{2} \text { or } \theta_{22} \\
\frac{-\left(n_{1}+n_{3}\right)}{2 n_{1}}\left[x(t)+n_{1}\right]=e(t) \cot \theta^{*}, \\
\text { if } \Delta x \leq 0 \text { and } \theta^{*} \text { is } \theta_{1} \text { or } \theta_{11} .
\end{array}\right.
\end{aligned}
$$

It is noted that the above Theorem 1 and Theorem 2 are valid regardless of the type of controller. The controller can be the classical PID controller or the intelligent controller. The following Section $\mathrm{V}$ will further elaborate the advantages of designing an intelligent fuzzy controller for NHS. 


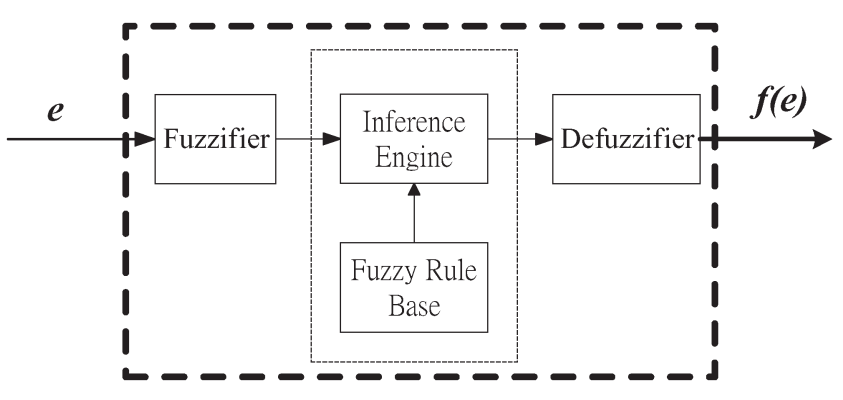

Fig. 8. Fuzzy logic controller.

\section{Synthesis of FuZZY LOGiC CONTROLler FOR NONLINEAR HYSTERETIC SYSTEMS}

For the past two decades, the FLC has been widely and successfully utilized and implemented in numerous industrial applications [21]-[24], [39], [40]. A general FLC consists of four modules: A fuzzification module, a fuzzy rule base, a fuzzy inference engine, and a defuzzification module [40]-[44], as shown in the dotted area in Fig. 8.

The $i$ th control rule $R^{i}$ in fuzzy controller in Fig. 8 has the following form:

$$
\begin{gathered}
R^{i}: I F x_{1} \text { is } A_{1}^{i} \text { and } \ldots \ldots x_{n} \text { is } A_{n}^{i} \text { THEN } y_{1} \text { is } W_{i 1} \\
\text { and } \ldots y_{m} \text { is } W_{i m}
\end{gathered}
$$

where $i$ is a rule number, $A_{q}^{i}$ are membership functions of antecedent part, and $W_{i p}$ are membership functions of the consequent part. In order to guarantee the stability of the closedloop system in Fig. 3 to control the NHS, we consider the following $2 N+1$ fuzzy IF-THEN rules:

$$
\text { IF } e \text { is } A_{1}^{i} \text { and } \Delta e \text { is } A_{2}^{i} \text { THEN } \Delta u \text { is } B^{\mathrm{i}}
$$

where $i=1,2, \ldots, 2 N+1$. The $2 N+1$ triangular membership functions for $e, \Delta e$, and $\Delta u$, respectively, are chosen in the following way.

That is, we use the $\mathrm{N}$ membership functions $A^{1}, \ldots, A^{\mathrm{N}}$ to cover the negative intervals $[\alpha, 0)$, the other $\mathrm{N}$ membership functions $A^{\mathrm{N}+2}, \ldots, \mathrm{A}^{\wedge}\{2\{\backslash \mathrm{rm} \mathrm{N}\}+1\}$ to cover the positive intervals $(0, \beta]$, and choose the center $\bar{x}^{N+1}$ of $A^{\mathrm{N}+1}$ equals to zero. Also, the centers $\bar{y}^{i}$ of fuzzy sets $B^{\mathrm{i}}$ are chosen such that

$$
\bar{y}^{i}=\left\{\begin{array}{ccc}
\leq 0 & \text { for } & i=1, \ldots, N \\
=0 & \text { for } & i=N+1 \\
\geq 0 & \text { for } & i=N+2, \ldots, 2 N+1
\end{array}\right.
$$

Lemma 1: [39]: If the fuzzy logic controller defined in Fig. 8, with their membership functions defined using (31), Fig. 9 and (32), then the fuzzy logic controller $f(e)$ using the center average defuzzifier (CAD) scheme will have the following properties:

(a) $f(0)=0$ and $e f(e) \geq 0$ for all $e \in R$.

(b) $\left|f\left(e_{1}\right)-f\left(e_{2}\right)\right| \leq \alpha\left|e_{1}-e_{2}\right|, \forall e_{1}, e_{2} \in R$, for some constant $\alpha$.

Although we have two input fuzzy variables, i.e., $e$ and $\Delta e$, in the fuzzy rule base, the validity of the above Lemma 1 still holds. Since the fuzzy variable $\Delta \boldsymbol{e}$ is generated inside the fuzzy controller, only the physical signal $e$ is shown in all the block diagrams in this paper.

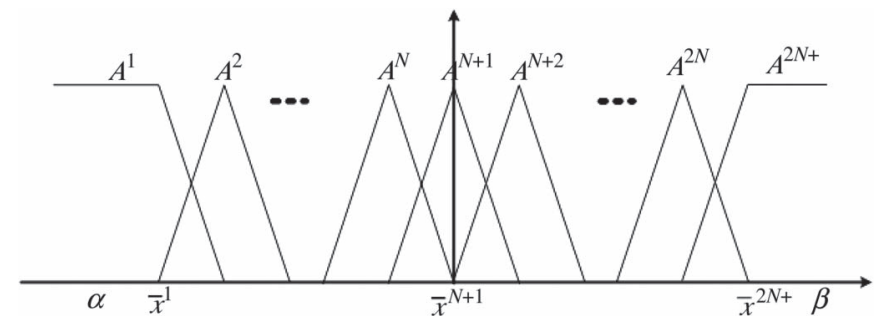

Fig. 9. Proposed triangular membership functions.

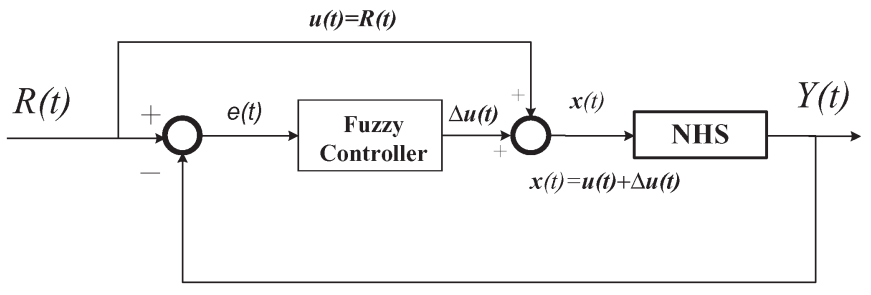

Fig. 10. NHS control system in Example 1.

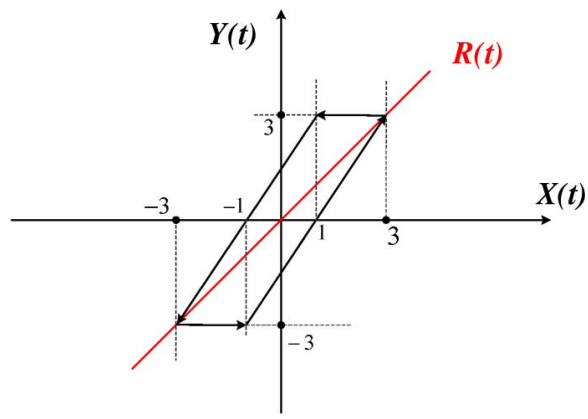

Fig. 11. NHS in Fig. 10.

Theorem 3: The closed-loop system shown in Fig. 3 using the fuzzy controller defined in Lemma 1 with the property of $\{\Delta u=f(e)=e \cot \theta, 0<\theta<\pi / 2\}$, will yield a asymptotical stable system, i.e., $\lim _{t \rightarrow \infty} e(t)=0$, in Fig. 3 .

Proof: The result is quite obvious from Theorem 1 and Lemma 1.

Q.E.D.

The condition of $f(e)=e \cot (\theta), 0<\theta<\pi / 2$ will be the guide to design the fuzzy rules using the configuration defined in Lemma 1.

Example 1: For the closed-loop system shown in the following Fig. 10.

It is desired to control the following NHS by using the above fuzzy controller (Fig. 11).

The membership functions for $e(t), \Delta e(t)$, and $\Delta u(t)$ are defined by the above (1), (2) and Figs. 9 and 12.

Table I shows the fuzzy rule table, which consists of $3^{2}=9$ rules for the two-input FLC. There are, however, only three major output membership functions for the consequent part.

The following Fig. 13 shows the simulation of Example 1 by letting

$$
R(t)= \begin{cases}3-0.3 * e^{5 t}, & \text { if } t \leq 0.6 \\ \sin (5 t)+2 \cos (20 t)+0.01 \sin (100 t), & \text { if } t>0.6\end{cases}
$$




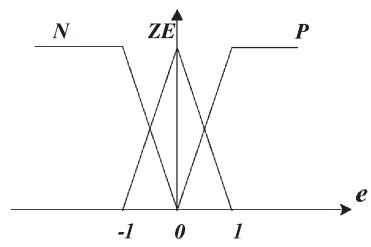

(a)

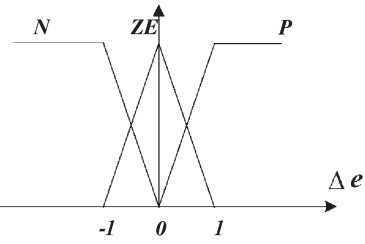

(b)

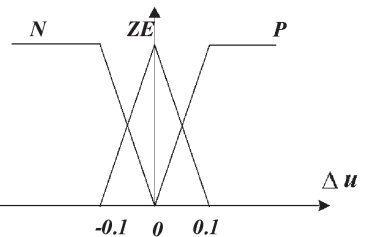

(c)

Fig. 12. Triangular membership functions for (a) $e(t)$, (b) $\Delta e(t)$, and (c) $\Delta u(t)$.

TABLE I

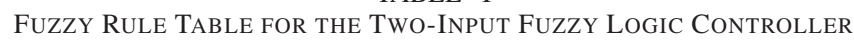

\begin{tabular}{|c|c|c|c|}
\hline $\boldsymbol{u} e$ & $\mathrm{~N}$ & $\mathrm{ZE}$ & $\mathrm{P}$ \\
\hline $\mathrm{N}$ & $\mathrm{N}$ & $\mathrm{ZE}$ & $\mathrm{ZE}$ \\
\hline $\mathrm{ZE}$ & $\mathrm{N}$ & $\mathrm{ZE}$ & $\mathrm{P}$ \\
\hline $\mathrm{P}$ & $\mathrm{ZE}$ & $\mathrm{ZE}$ & $\mathrm{P}$ \\
\hline
\end{tabular}

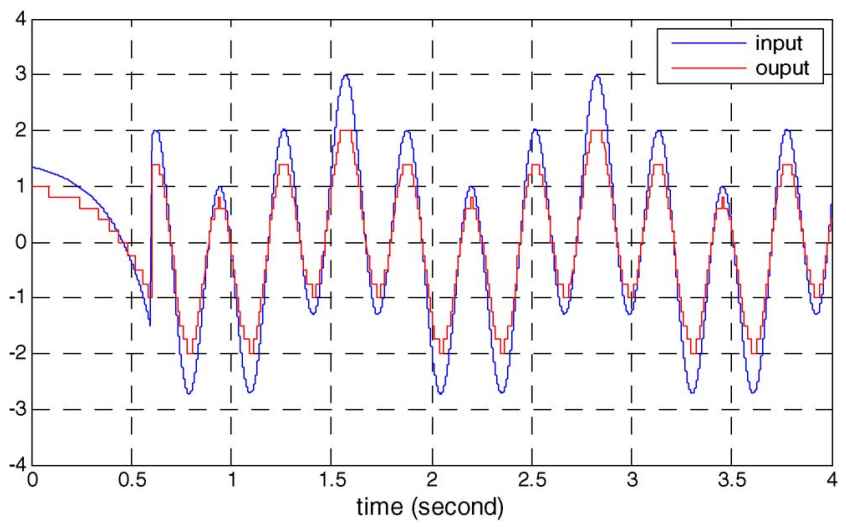

Fig. 13. Response with $(d f 2, d f 0, d f 1)=(-1.5,0,1.5)$.

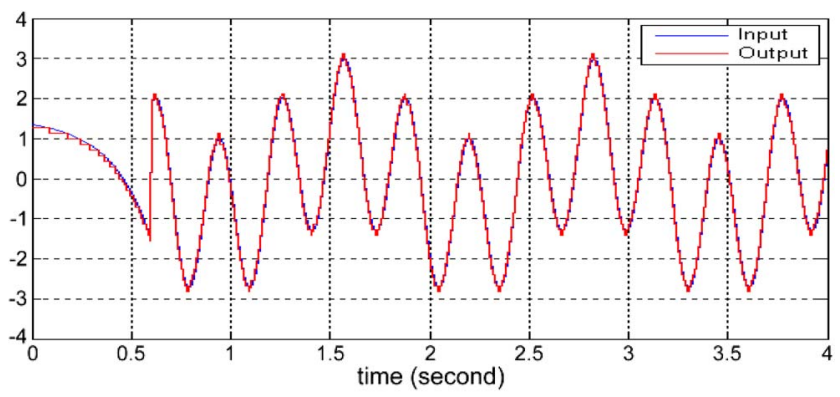

Fig. 14. Tracking performance in Example 1.

The above complicated $R(t)$ is to mimic the pedal signals by automobile drivers. In the first time, the $(\mathbf{d f} \mathbf{2}, \mathbf{d f 0} \mathbf{d}, \mathbf{d f 1})=$ $(-1.5,0,1.5)$, and the response is shown in Fig. 13.

Then, we let $(\mathbf{d f} \mathbf{2}, \mathbf{d f 0}, \mathbf{d f} \mathbf{1})=(-0.1,0,0.1)$ again, and the response is shown in Fig. 14. It is obvious that excellent tracking performance after changing the values of $(\mathbf{d f} \mathbf{2}, \mathbf{d f 0}, \mathbf{d f} \mathbf{1})$ from $(-1.5,0,1.5)$ to $(-0.1,0,0.1)$. is obtained by using the above stable fuzzy controller. And the curves of $\boldsymbol{e}$ and $f(\boldsymbol{e})$ in Example 1 are shown in Fig. 15.

The condition of $\{e f(e) \geq 0, f(0)=0\}$ is obviously true in Fig. 15, where $(\mathbf{d f 2}$, df0, df1 $)=(-0.1,0,0.1)$. Through comparing the responses in Figs. 13 and 14, the different linguistic hedge dfi have the different control effects. Because

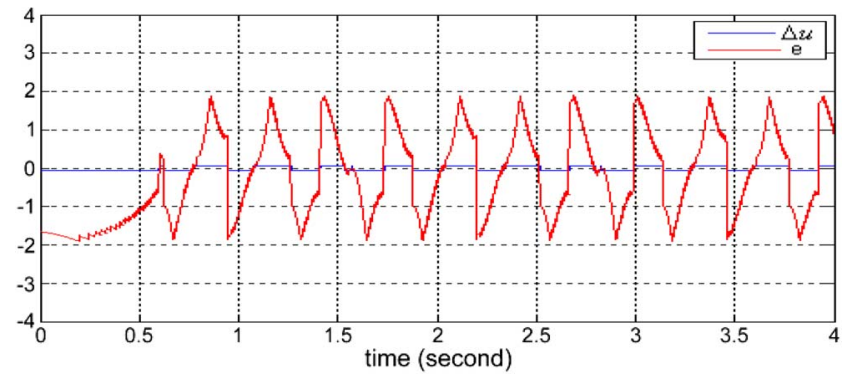

Fig. 15. Curves of $\boldsymbol{e}$ and $\Delta u=f(\boldsymbol{e})$ in Example 1 .

the dfi in the $\Delta u$ will decide the performance, we need to tune the dfi to realize the FLC controller. Next, we will need a new back-propagation algorithm to fine tune dfi to complete the controller design so as to track the input signal in good performance. This new control strategy will be adopted to control real world device, i.e., the nonlinear hysteretic ET for modern automobiles.

\section{Fine Tuning the Centers of Fuzzy Output MFs}

In this paper, the $\mathrm{CAD}$ is adopted to determine the defuzzifier output $\Delta u[39]$. Since Theorem 1 shows the existence of $\Delta u$ of the output of the FLC to eliminate the nonlinear hysteretic phonemenon in Fig. 3. To realize a better $\Delta u$ to achieve better tracking performance, we choose to fine tune the center of the output Membership functions (MFs) to minimize the errors by a sinusoidal training signal. The reason to choose a sinusoidal training signal to fine tune the output MFs is that the pedal signals by the drivers are the up-and-down signals, which is actually the distorted sinusoidal signal. The new backpropagation algorithm to tune the output MFs of the FLC can be proceeded as follows:

$$
\begin{aligned}
d_{i}(t+1) & =d_{i}(t)-\eta \frac{\partial e^{2}(t)}{\partial d_{i}} \\
& =d_{i}(t)-2 \eta * e(t) * \frac{\partial e(t)}{\partial d_{i}}
\end{aligned}
$$

where e $(t)$ is defined in (1) in Fig. 3, di(t) is the center of the ith output MF, and $\eta$ is the learning rate. And we can have

$$
\frac{\partial e(t)}{\partial d_{i}}=\frac{\partial(R-Y)}{\partial d_{i}}=\frac{\partial(-Y)}{\partial d_{i}}=-\frac{\partial[N H S(u+\Delta u)]}{\partial d_{i}} .
$$

Assuming that we have the following symmetric NHS like Fig. 16.

When $\Delta x>0$, we have the following three cases.

Case 1: $-n_{1} \leq x \leq-n_{2}$, then from (34), we have

$$
\frac{\partial e(t)}{\partial d_{i}}=\frac{w_{i}}{\sum w_{i}} \text {. }
$$




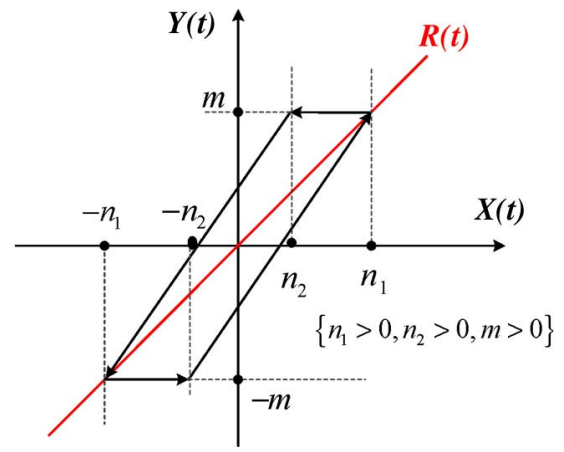

Fig. 16. NHS for fine tuning the centers of output MFs.

Therefore, we have the following equation from (33)

$$
d_{i}(t+1)=d_{i}(t)-2 \eta *\left(\frac{m}{n_{1}}\left[x(t)+n_{1}\right]\right) \frac{w_{i}}{\sum w_{i}} .
$$

Case 2: $-n_{2} \leq x \leq n_{1}$, then from (34), we have

$$
\frac{\partial e(t)}{\partial d_{i}}=\frac{w_{i}}{\sum w_{i}} .
$$

Therefore, we have the following equation from (33)

$$
d_{i}(t+1)=d_{i}(t)-2 \eta *\left(\frac{m\left(n_{2}-n_{1}\right)}{n_{1}\left(n_{2}+n_{1}\right)}\left[x(t)-n_{1}\right]\right) \frac{w_{i}}{\sum w_{i}} .
$$

Case 3: $x \geq n_{1}$, or $x \leq-n_{2}$ then from (33) and (34), we have

$$
d_{i}(t+1)=d_{i}(t) \text { due to } \frac{\partial e(t)}{\partial d_{i}}=0 \text {. }
$$

When $\Delta x<0$, we have the following three cases.

Case 4: $n_{2} \leq x \leq n_{1}$, then from (34), we have

$$
\frac{\partial e(t)}{\partial d_{i}}=\frac{w_{i}}{\sum w_{i}} \text {. }
$$

Therefore, we have the following equation from (33).

$$
d_{i}(t+1)=d_{i}(t)-2 \eta *\left(\frac{m}{n_{1}}\left[x(t)-n_{1}\right]\right) \frac{w_{i}}{\sum w_{i}} .
$$

Case 5: $-n_{1} \leq x \leq n_{2}$, then from (34), we have

$$
\frac{\partial e(t)}{\partial d_{i}}=\frac{w_{i}}{\sum w_{i}} \text {. }
$$

Therefore, we have the following equation from (33):

$d_{i}(t+1)=d_{i}(t)-2 \eta *\left(\frac{m\left(n_{2}-n_{1}\right)}{n_{1}\left(n_{2}+n_{1}\right)}\left[x(t)+n_{1}\right]\right){\frac{w_{i}}{\sum w_{i}}}^{\circ}$.

Case 6: $x \leq-n_{1}$, or $x \geq n_{2}$, then from (33) and (34), we have

$$
\left.d_{i}(t+1)=d_{i} t\right) \text { due to } \frac{\partial e(t)}{\partial d_{i}}=0 \text {. }
$$

It is quite obvious that the update of the center of ith output MFs, i.e., $d_{i}$, for the above cases is quite obvious from the above cases. The following Example 2 is illustrated to go through the sinusoidal training process and tested by the same pedal signal $R(t)$ adopted in Example 1 .

Example 2: The closed-loop system is shown in Fig. 10. It is desired to find the fuzzy controller to cancel the NHS effects as shown in Fig. 17, so that we can have a good tracking performance.

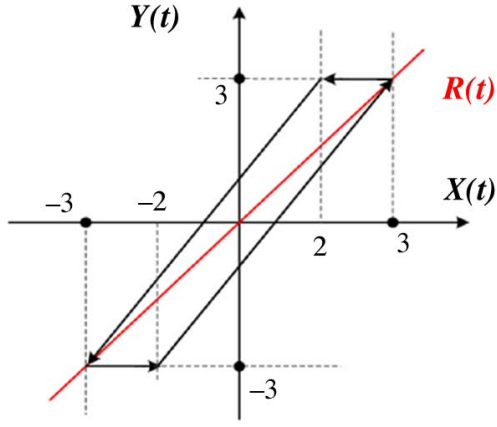

Fig. 17. NHS in Fig. 10.

The membership functions for $e(t), \Delta e(t)$, and $\Delta u(t)$ are defined the same as in Example 1, which is shown in Fig. 18.

In this example, we let $(d f 2, d f 0, d f 1)=(-1,0,1)$ initially. The control effect of this initial FLC is shown in Fig. 19, which shows bad tracking performance. By using the sinusoidal signal $3 \sin (7 t)$ as the training signal to go through the above backpropagation tuning process with learning rate $\eta=0.00112$, the final updated values of (df2, df0, df1) becomes $(-0.13928$, $0.011291,0.15057)$. The converged processes of fine tuning using $3 \sin (7 t)$ is shown in Figs. 20 and 21.

Fig. 21 shows excellent tracking performance using $(d f 2, d f 0, d f 1)=(-0.13928,0.011291,0.15057)$ with pedal signal as input signal. It is quite obvious that the tracking performance has been dramatically enhanced from Figs. 19-21.

\section{SySTEM IDENTIFICATION OF NHS ELECTRONIC THROTTLE}

In order to achieve the control of the nonlinear ET, we need to perform the system identification of the ET in open-loop mode. This can be done by using the dSpace MABX [31] under Simulink in Matlab. Fig. 22 shows the connection of PC (under Windows), MABX, and the nonlinear ET.

The basic theme is to generate a PWM signal with varying duty cycles as the input signal for the nonlinear ET. The turning angle of the nonlinear ET will be read back from its internal sensor and recorded in a log file. As shown in Fig. 23, we can gather the nonlinear hysteretic loop from the ET in Fig. 24.

One of the major factors of the hysteretic of ET is the return spring. The controller will need more energy to resist the force from the return spring during acceleration. However, the controller will spend less energy to release valve of ET during deceleration, since the return spring will automatically pull the valve back to its closed position. The other reason is due to the copper coils inside the BLDC. This open-loop control can be described by the following Fig. 24. When the nonlinear ET is from close to open, the controller receives the pedal signals and throttle signals. Then, the controller sends the consistent duty signal, which is PWM to the H-bridge circuit and drives the throttle to operate in the correct position. When the nonlinear ET is from open to close, the controller also does the same action as above but using different settings due to the hysteretic loop in ET as described above.

It is noted that although the hysteretic loop shown in Fig. 24 is different from that in Fig. 2, all the properties discussed above, such as Theorem 1 and Theorem 2, are still valid. 


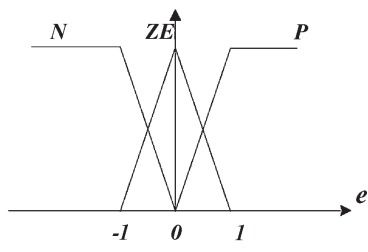

(a)

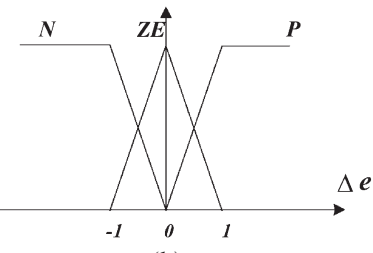

(b)

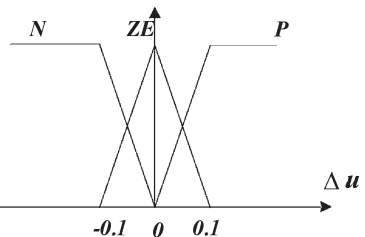

(c)

Fig. 18. Triangular membership functions for (a) $e(t)$, (b) $\Delta e(t)$, and (c) $\Delta u(t)$.

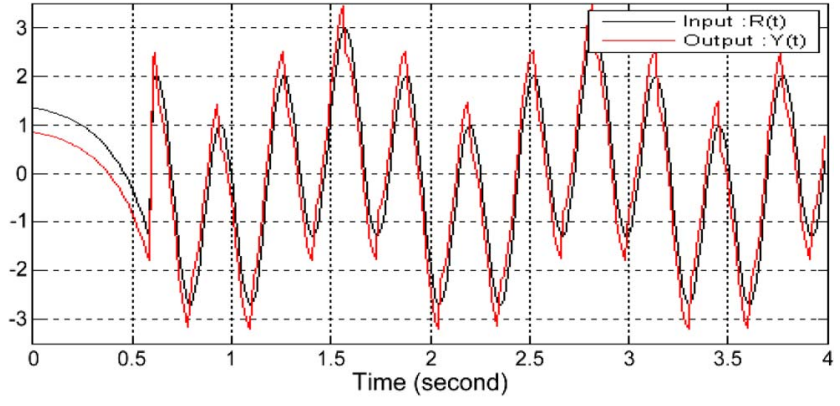

Fig. 19. Bad tracking performance using initial $(d f 2, d f 0, d f 1)=(-1,0,+1)$.

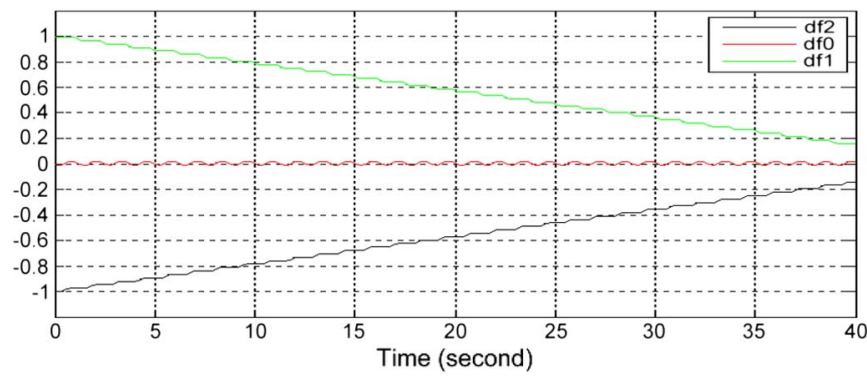

Fig. 20. Convergence process of (df2, df0, df1) using training signal $3 \sin (7 t)$.

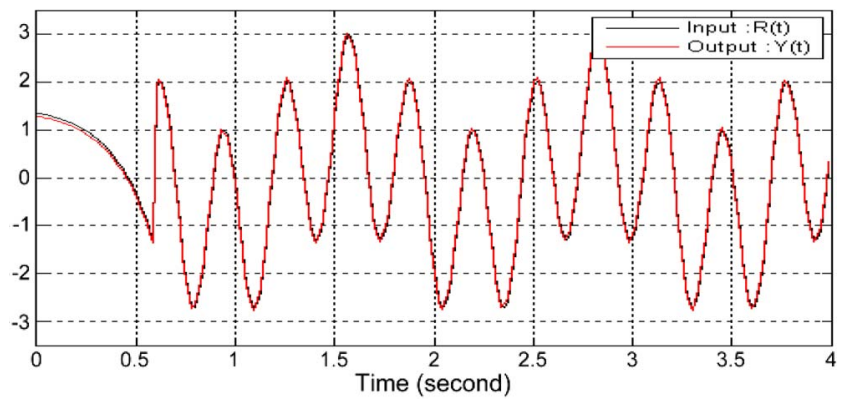

Fig. 21. Excellent tracking performance using $(d f 2, d f 0, d f 1)=$ $(-0.13928,0.011291,0.15057)$ with pedal signal as input signal.

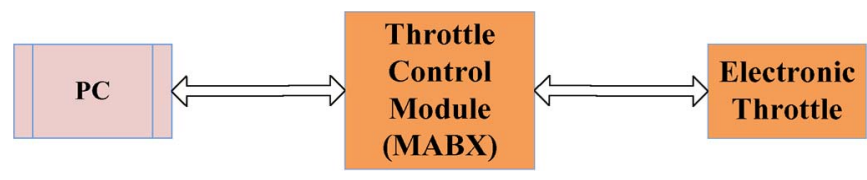

Fig. 22. System identification of ET using MABX.

\section{Closed-Loop CONTROL USING FUZZY LOGIC CONTROLLER FOR ET}

The following Fig. 25 shows the closed-loop control of the nonlinear hysteretic ET using FLC.

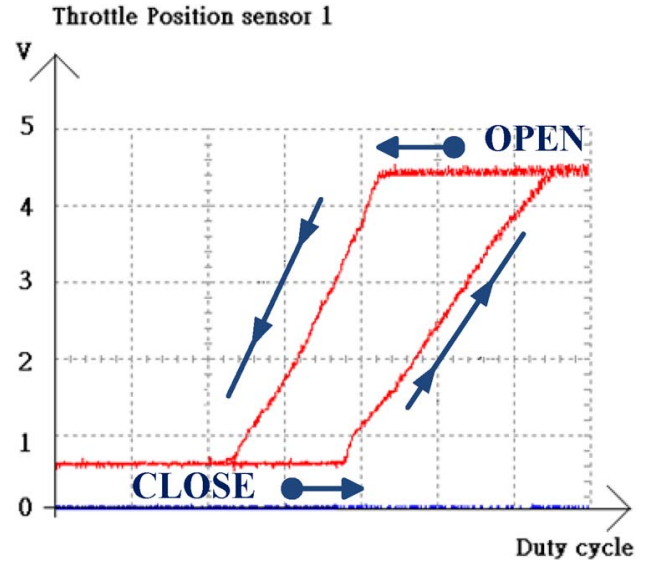

Fig. 23. Hysteretic loop of ET.

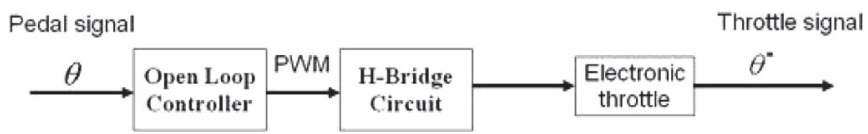

Fig. 24. Open-loop control for nonlinear ET.

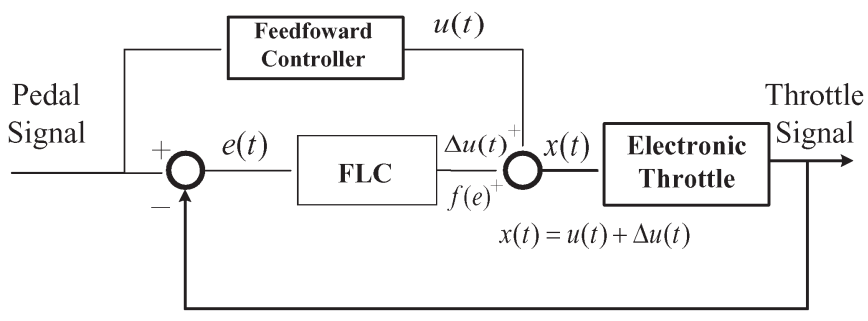

Fig. 25. Closed-loop control nonlinear ET using FLC.

A controller compares the throttle signal $(\mathrm{Y}(\mathrm{t}))$ with the pedal signal $(\mathrm{R}(\mathrm{t}))$ and produces the control signal to minimize the error. The equations for $e(k), \Delta e(k)$ are

$$
e(k)=T(k)-P(k) ; \quad \Delta e(k)=e(k)-e(k-1)
$$

where $k$ is the sampling instant of the process. The variables $e(k), \Delta e(k)$ are the conditions monitored by the FLC. These conditions are expressed in terms of linguistic variables as negative large (NL), negative medium (NM), negative small (NS), zero (ZE), positive small (PS), positive medium (PM), positive large (PL). The five membership functions $\{\mathrm{NL}, \mathrm{NM}$, ZE, PM, PL $\}$ of $e$ and $\Delta e$ are shown in Fig. 26(a) and (b). The seven membership functions $\{\mathrm{NL}, \mathrm{NM}, \mathrm{NS} Z \mathrm{ZE}, \mathrm{PS}, \mathrm{PM}, \mathrm{PL}\}$ of output $\Delta u$ are shown in Fig. 26(c).

Fig. 26 shows the symmetrical triangular membership functions with $50 \%$ overlap with neighboring membership functions for FLC. It is obvious from Theorem 2 that this is the stable fuzzy controller which satisfies the constraint of 


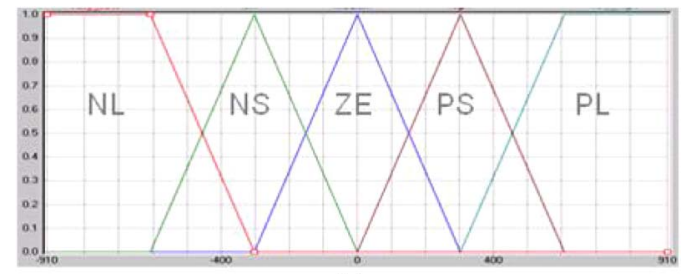

(a)

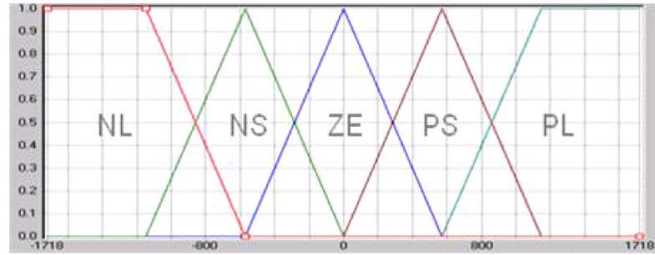

(b)

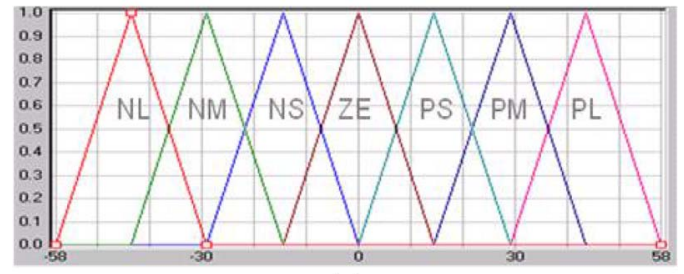

(c)

Fig. 26. Symmetrical triangular membership functions for: (a) $e(k)$, (b) $\Delta e(k),($ c) $\Delta u(k)$ of FLC.

TABLE II

Rule BASE FOR FLC TO CONTROL THE NONLINEAR ET

\begin{tabular}{|c|c|c|c|c|c|}
\hline \multicolumn{1}{c|}{$\mathrm{N}^{\mathrm{N}}$} & NL & NM & ZE & PM & PL \\
\hline NM & NS & NS & NS & ZE & ZE \\
\hline ZE & ZE & ZE & ZE & PS & PS \\
\hline PM & PS & ZE & ZE & PS & PM \\
\hline PL & PS & PS & PS & PM & PL \\
\hline
\end{tabular}

$\{e f(e) \geq 0, f(0)=0\}$. The control signal is in the fuzzified form. To convert this into a crisp form, the center averaging defuzzification scheme is used. For this FLC, we have $7^{2}=$ 49 rules, which are shown in Table II. In order to regulate the output of FLC, i.e., $\Delta u$, to follow the trend of $\{\Delta u=$ $f(e)=e \cot (\theta), 0<\theta<\pi / 2\}$, the membership functions of $\Delta u$ shown in Fig. 26(c) are updated several times to yield a satisfactory tracking performance.

For comparison purpose, the linearized transfer function of the ET is obtained from Matlab system identification toolbox as

$$
G(s)=\frac{-6.112 s^{2}-21.75 s-3.168}{s^{3}+4.239^{2}+9.412 s-2.322} .
$$

Therefore, a linear PID controller can also be obtained as

$$
\begin{aligned}
C(s) & =K_{p}+K_{I} / s+K_{d} s \\
& =-0.8833-0.0506 / s-1.0235 s
\end{aligned}
$$

The tracking performances will be compared in the following section.

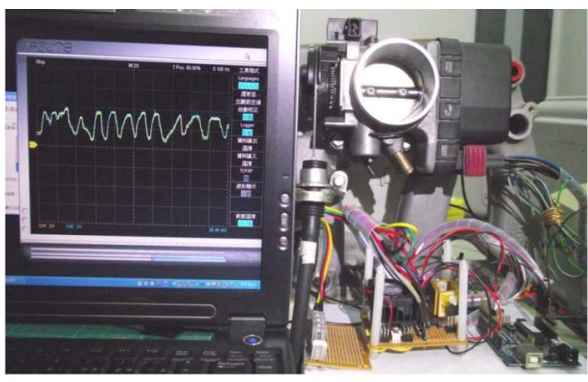

(a)

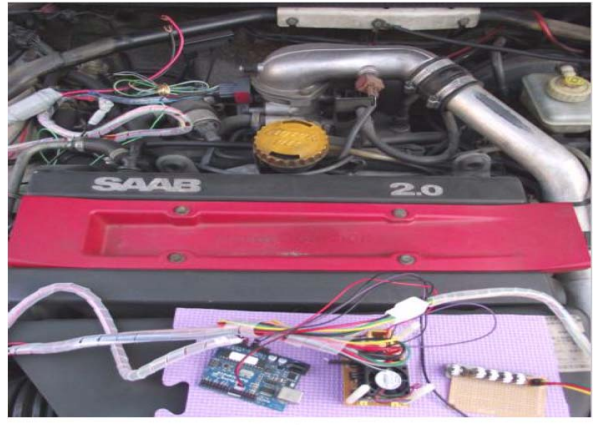

(b)

Fig. 27 (a) ETC in laboratory. (b) Real-time ETC in Saab 9000.

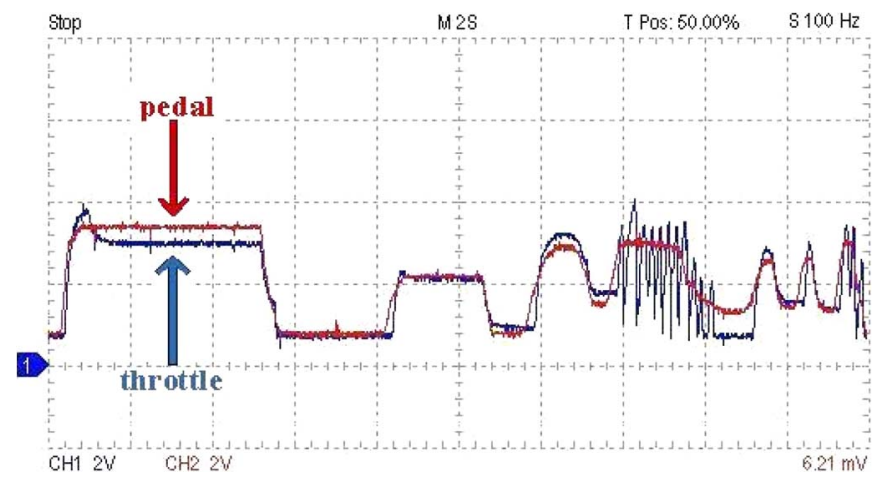

Fig. 28. Tracking performance of PID controller.

\section{BENCHMARK EXPERIMENTS}

Fig. 27(a) shows the ET and experiment plant adopted in our experiment. The real-time signal processing is carried out by an advanced microcontroller development board, in which the fuzzy controller can be easily coded in the form of fix point integer. Fig. 27(b) shows our ET and control circuits, which are set up on our experiment car. However, for the tracking performance of PID controller as shown in (36), we still need the expensive MABX to act as the real-time controller.

The real-time tracking is performed in this experiment using random pedal signals to simulate the real actions of automobile drivers. The tracking of the PID controller is shown in Fig. 28 with the red line representing the pedal signal and the blue line representing the throttle signal.

In the processes of designing the fuzzy controllers, the following plots show three different parameter variations. The 3-D plots show different controller actions due to different fuzzy membership functions. The associated real-time responses are also displayed. 


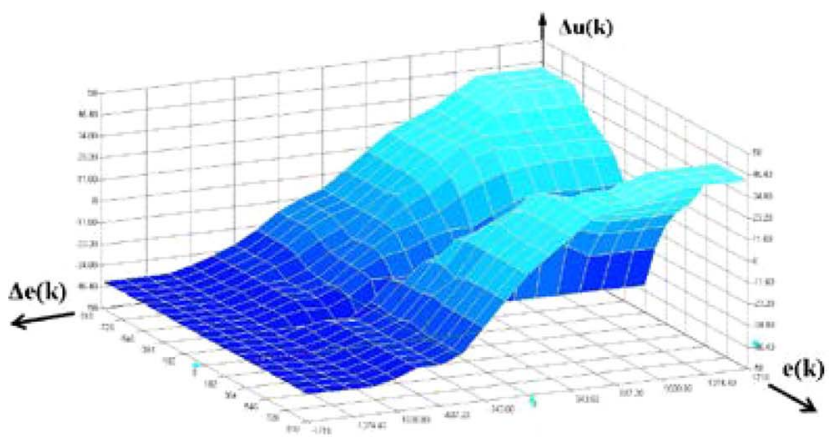

(a)

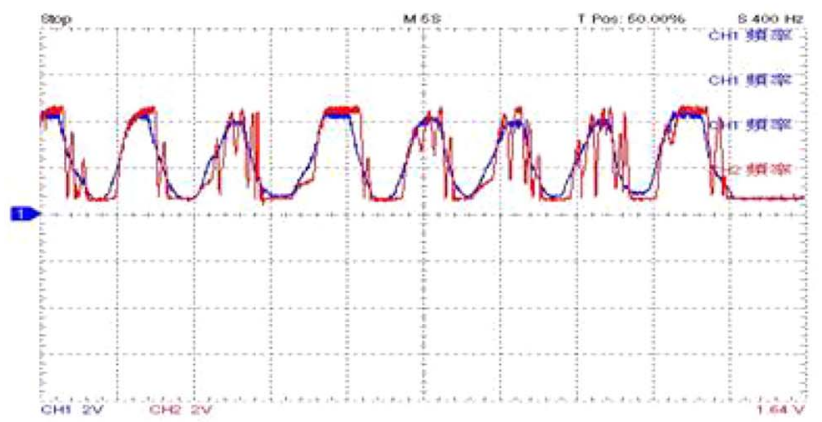

$(a-1)$

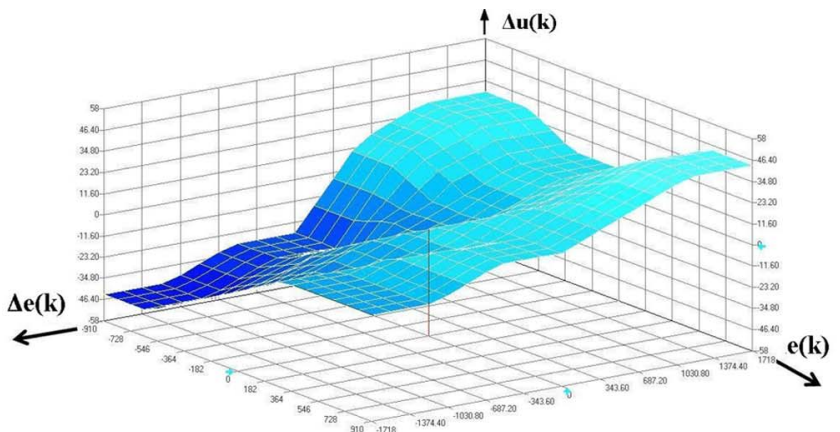

(b)

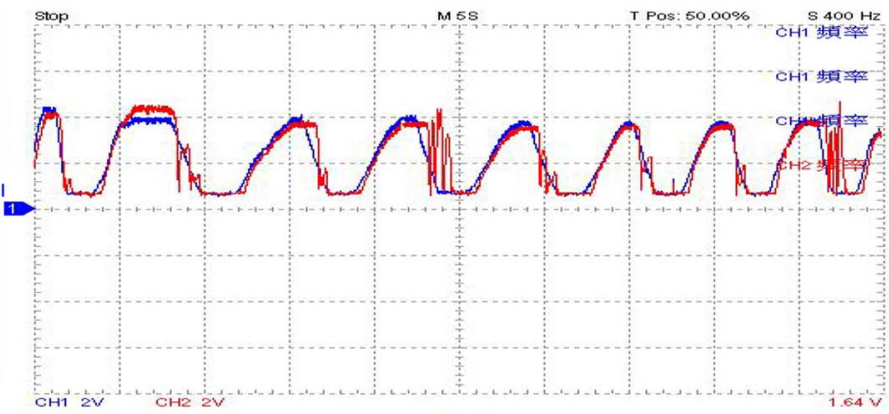

(b-1)

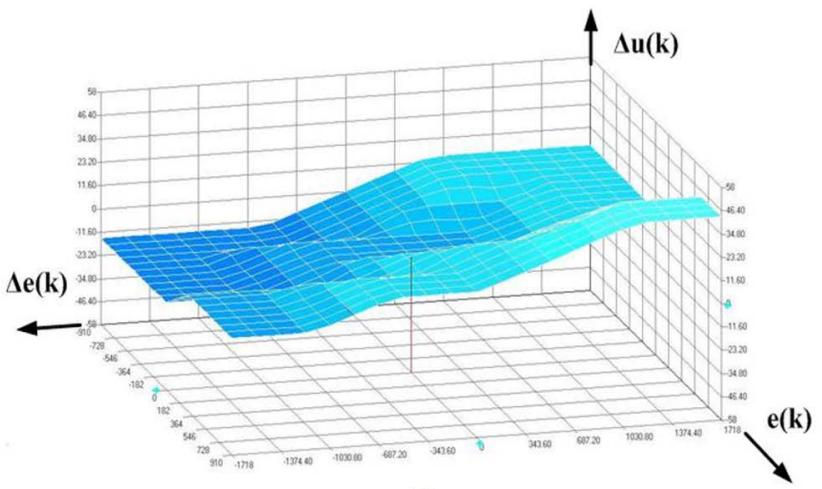

(c)

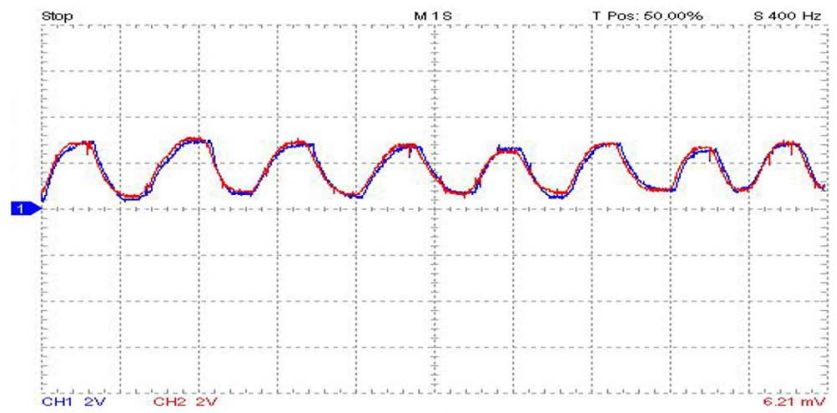

(c-1)

Fig. 29. Three variations of fuzzy controller with their associated real-time responses.

It is obvious that the third fuzzy controller in Fig. 29 shows the best tracking result, although all the three fuzzy controllers show stable tracking results, as predicted from Theorem 1. The best tracking performance of FLC is shown in Fig. 30 with the red line representing the pedal signal and the blue line representing the throttle signal.
From the above real-time experimental results of PID and fuzzy controllers, we can get the comparative table between them in Table III.

It is obvious from Figs. 28 and 30 that the FLC can have a better tracking performance with very less cost than that of PID controller, which is designed from the expensive MABX. 
TABLE III

Comparative TABle BETWEEN THE EXPERIMENT RESUlTS OF PID AND FUZZY CONTROLLERS

\begin{tabular}{c|cc}
\hline Controller & Error Rate (\%) & Success Rate (\%) \\
\hline PID & 10.164 & 89.836 \\
Fuzzy & 1.951 & 98.049 \\
\hline
\end{tabular}

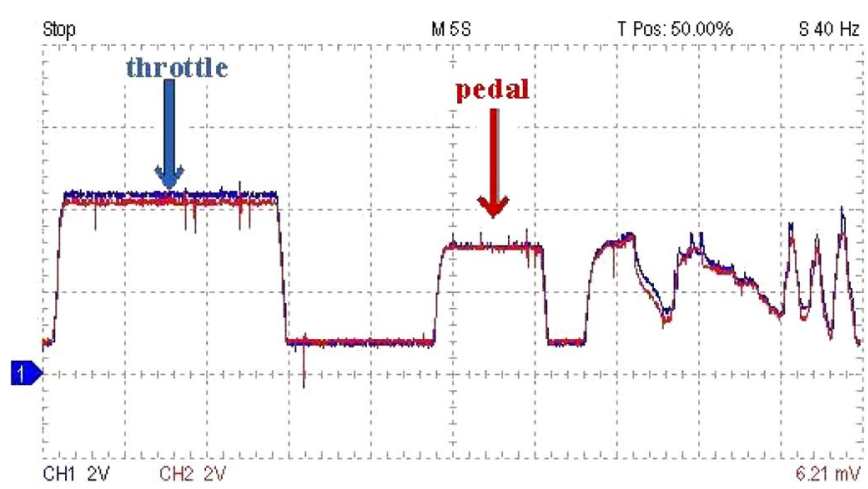

Fig. 30. Excellent tracking performance of ETC using FLC.

\section{CONClusion}

The intelligent control of industrial nonlinear ETs is designed and implemented in this paper. The experimental result shows that a stable fuzzy logic control can be realized to control the nonlinear hysteretic BLDC motor adopted in industrial ETs. The control strategy of a NHS is first investigated which can be used to systematically realize a stable FLC. The simulation of the stable FLC to control a NHS is first validated using computer simulation. The input signal is specially fabricated to mimic the pedal signals by automobile drivers. The successful results then carried over to the real-time implementation of FLC to control a real ET in Saab 95. The stable FLC is implemented using an advanced microcontroller development board at the minimum cost for real commercial applications. In order to compare the tracking results, a PID controller is also obtained using Matlab System Identification Toolbox and executed using dSpace MABX. It is obvious that the tracking results using FLC is much better than that using PID controller.

\section{REFERENCES}

[1] X. Yuan and Y. Wang, "A novel electronic-throttle-valve controller based on approximate model method," IEEE Trans. Ind. Electron., vol. 56, no. 3, pp. 883-890, Mar. 2009.

[2] N. Mutoh, Y. Hayano, H. Yahagi, and K. Takita, "Electric braking control methods for electric vehicles with independently driven front and rear wheels," IEEE Trans. Ind. Electron., vol. 54, no. 2, pp. 1168-1172, Apr. 2007

[3] M. Vašak, M. Baotiá, I. Petroviá, and N. Periá, "Hybrid theory-based time-optimal control of an electronic throttle," IEEE Trans. Ind. Electron., vol. 54, no. 3, pp. 1483-1494, Jun. 2007.

[4] C. Alippi, C. de Russis, and V. Piuri, "A neural-network based control solution to air-fuel ratio control for automotive fuel-injection systems," IEEE Trans. Syst., Man, Cybern. C, Appl. Rev., vol. 33, no. 2, pp. 259268, May 2003.

[5] W.-Y. Wang, Y.-H. Chien, M.-C. Chen, and T.-T. Lee, "Control of uncertain active suspension system with anti-lock braking system using fuzzy neural controllers," in Proc. IEEE Int. Conf. Syst., Man, Cybern., Oct. 2009, pp. 3371-3376.

[6] G. Xie, F. Wang, and K. Xie, "RST-based system design of hybrid intelligent control," in Proc. IEEE Int. Conf. Syst., Man, Cybern., 2004, vol. 6, pp. 5800-5805.
[7] Z. Ye, "Modeling, identification, design, and implementation of nonlinear automotive idle speed control systems-An overview," IEEE Trans. Syst., Man, Cybern. C, Appl. Rev., vol. 37, no. 6, pp. 1137-1151, Nov. 2007.

[8] R. Subbu, K. Goebel, and D. K. Frederick, "Evolutionary design and optimization of aircraft engine controllers," IEEE Trans. Syst., Man, Cybern. C, Appl. Rev., vol. 35, no. 4, pp. 554-565, Nov. 2005.

[9] L. Cai, A. B. Rad, and W.-L. Chan, "An intelligent longitudinal controller for application in semiautonomous vehicles," IEEE Trans. Ind. Electron., vol. 57, no. 4, pp. 1487-1497, Apr. 2011.

[10] V. Milanes, J. Villagra, J. Perez, and C. Gonzalez, "Low-speed longitudinal controllers for mass-produced cars: A comparative study," IEEE Trans. Ind. Electron., vol. 59, no. 1, pp. 620-628, Jan. 2012.

[11] M. Corno, M. Tanelli, S. M. Savaresi, and L. Fabbri, "Design and validation of a gain-scheduled controller for the electronic throttle body in rideby-wire racing motorcycles," IEEE Trans. Control Syst. Technol., vol. 19, no. 1, pp. 18-30, Jan. 2011.

[12] X. Yuan, Y. Wang, W. Sun, and L. Wu, "RBF networks-based adaptive inverse model control system for electronic throttle," IEEE Trans. Control Syst. Technol., vol. 18, no. 3, pp. 750-756, May 2010.

[13] M. A. Rizvi, A. I. Bhatti, and Q. R. Butt, "Hybrid model of the gasoline engine for misfire detection," IEEE Trans. Ind. Electron., vol. 58, no. 8, pp. 3680-3692, Aug. 2011

[14] R. Hoseinnezhad and A. Bab-Hadiashar, "Efficient antilock braking by direct maximization of tire-road frictions," IEEE Trans. Ind. Electron., vol. 58, no. 8, pp. 3593-3600, Aug. 2011.

[15] R. K. Jardan, P. Stumpf, P. Bartal, Z. Varga, and I. Nagy, "A novel approach in studying the effects of subharmonics on ultrahigh-speed AC motor drives," IEEE Trans. Ind. Electron., vol. 58, no. 4, pp. 1274-1281, Apr. 2011.

[16] T. Aono and T. Kowatari, "Throttle-control algorithm for improving engine response based on air-intake model and throttle-response model," IEEE Trans. Ind. Electron., vol. 53, no. 3, pp. 915-921, Jun. 2006.

[17] Y. Pan, U. Ozguner, and O. H. Dagci, "Variable-structure control of electronic throttle valve," IEEE Trans. Ind. Electron., vol. 55, no. 11, pp. 3899-3907, Nov. 2008.

[18] R.-J. Lian, "Intelligent controller for robotic motion control," IEEE Trans. Ind. Electron., vol. 58, no. 11, pp. 5220-5230, Nov. 2011.

[19] X. Lu and M. Huang, "System-decomposition-based multilevel control for hydraulic press machine," IEEE Trans. Ind. Electron., vol. 59, no. 4, pp. 1980-1987, Apr. 2012.

[20] Q. Ahmed and A. I. Bhatti, "Estimating SI engine efficiencies and parameters in second-order sliding modes," IEEE Trans. Ind. Electron., vol. 58, no. 10, pp. 4837-4846, Aug. 2011.

[21] S. G. Goodridge, M. G. Kay, and R. C. Luo, "Multilayered fuzzy behavior fusion for real-time reactive control of systems with multiple sensors," IEEE Trans. Ind. Electron., vol. 43, no. 3, pp. 387-394, Jun. 1996.

[22] R. C. Luo and T. M. Chen, "Autonomous mobile target tracking system based on grey-fuzzy control algorithm," IEEE Trans. Ind. Electron., vol. 47, no. 4, pp. 920-931, Aug. 2000.

[23] O. Kaynak, K. Erbatur, and M. Ertugrul, "The fusion of computationally intelligent methodologies and sliding-mode control-A survey," IEEE Trans. Ind. Electron., vol. 48, no. 1, pp. 4-17, Feb. 2001.

[24] C.-H. Wang and D.-Y. Huang, "Intelligent control of nonlinear hysteretic electronic throttle using brushless DC motor (ET-BLDC)," in Proc. IEEE Conf. IECON, Nov. 2010, pp. 156-161.

[25] M. Vasak, M. Baotic, M. Morari, I. Petrovic, and N. Peric, "Constrained optimal control of an electronic throttle," Int. J. Control, vol. 79, no. 5, pp. 465-478, May 2006.

[26] D. Kim, H. Peng, S. Bai, and J. M. Maguire, "Control of integrated powertrain with electronic throttle and automatic transmission," IEEE Trans. Control Syst. Technol., vol. 15, no. 3, pp. 474-482, May 2007.

[27] J. Deur, D. Pavkovic, N. Peric, M. Jansz, and D. Hrovat, "An electronic throttle control strategy including compensation of friction and limphome effects," IEEE Trans. Ind. Appl., vol. 40, no. 3, pp. 821-834, May/Jun. 2004.

[28] D. Pavkovic, J. Deur, M. Jansz, and N. Peric, "Adaptive control of automotive electronic throttle," Control Eng. Pract., vol. 14, no. 2, pp. 121-136, Feb. 2006.

[29] U. Ozguner, S. Hong, and Y. Pan, "Discrete-time sliding mode control of electronic throttle valve," in Proc. 40th IEEE Conf. Decision Control, Orlando, FL, 2001, pp. 1819-1824.

[30] K. Nakano, U. Sawut, K. Higuchi, and Y. Okajima, "Modeling and observer-based sliding-mode control of electronic throttle systems," ECTI Trans. Elect. Eng. Eletron. Commun., vol. 4, no. 1, pp. 22-28, 2006.

[31] M. Baric, I. Petrovic, and N. Peric, "Neural network-based sliding mode control of electronic throttle," Eng. Appl. Artif. Intell., vol. 18, no. 8, pp. 951-961, Dec. 2005. 
[32] M. Baric, I. Petrovic, and N. Peric, "Neural network based sliding mode control of an electronic throttle," in Proc. IFAC Symp. Adv. Autom. Control, Salerno, Italy, 2004, pp. 176-182.

[33] D. V. Prokhorov, "Training recurrent neurocontrollers for real-time applications," IEEE Trans. Neural Netw., vol. 18, no. 4, pp. 1003-1015, Jul. 2007.

[34] Saab, Saab 9-5 SERVICE MANUAL, 1998.

[35] dSPACE company website. [Online]. Available: http://www.dspaceinc. $\mathrm{com} /$

[36] G. Navarro and M. Manic, "FuSnap: Fuzzy control of logical volume snapshot replication for disk arrays," IEEE Trans. Ind. Electron., vol. 58, no. 9, pp. 4436-4444, Sep. 2011.

[37] T. Orowska-Kowalska, M. Kaminski, and K. Szabat, "Implementation of a sliding-mode controller with an integral function and fuzzy gain value for the electrical drive with an elastic joint," IEEE Trans. Ind. Electron., vol. 57, no. 4, pp. 1309-1317, Apr. 2011.

[38] The MathWorks website. [Online]. Available: http://www.mathworks. $\mathrm{com} /$

[39] L.-X. Wang, A Course in Fuzzy Systems and Control. Englewood Cliffs, NJ: Prentice-Hall, 1997

[40] Y. H. Bharathi, B. R. Rekha, P. Bhaskar, C. S. Parvathi, and A. B. Kulkarni, "Multi-input fuzzy logic controller for brushless DC motor drives," Defence Sci. J., vol. 58, no. 1, pp. 147-158, Jan. 2008.

[41] A. J. Sengstacken, D. A. DeLaurentis, and M.-R. Akbarzadeh-T, "Fuzzy logic control for shared-autonomy in automotive swarm environment," in Proc. IEEE Int. Conf. Syst., Man, Cybern., 2007, pp. 196-201.

[42] S.-J. Wu, G.-Z. Zeng, H.-H. Chiang, and T.-T. Lee, "Application of optimal fuzzy tracking control for automotive driving," in Proc. IEEE Int. Conf. Syst., Man, Cybern., 2005, vol. 4, pp. 3319-3324.

[43] J. C. Ervin and S. E. Alptekin, "Fuzzy logic control of a model airplane," in Proc. IEEE Int. Conf. Syst., Man, Cybern., 1998, vol. 3, pp. 2320-3325.

[44] D. E. Nelson, R. Challoo, R. A. McLauchlan, and S. I. Omar, "Implementation of fuzzy logic for an antilock braking system," in Proc. IEEE Int. Conf. Syst., Man, Cybern., 1997, vol. 4, pp. 3680-3685.

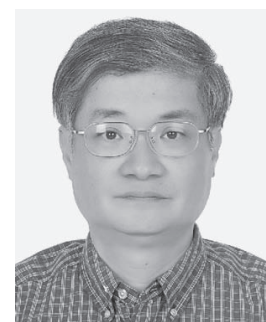

Chi-Hsu Wang (M'92-SM'93-F'08) was born in Tainan, Taiwan, in 1954. He received the B.S. degree in control engineering from National Chiao Tung University, Hsinchu, Taiwan, the M.S. degree in computer science from the National Tsing Hua University, Hsinchu, Taiwan, and the Ph.D. degree in electrical and computer engineering from the University of Wisconsin, Madison, in 1976, 1978, and 1986, respectively.

He was appointed Associate Professor in 1986, and Professor in 1990, in the Department of Electrical Engineering, National Taiwan University of Science and Technology, Taipei, Taiwan. He is currently a Professor in the Department of Electrical Engineering, National Chiao Tung University, Hsinchu, Taiwan. His current research interests and publications are in the areas of digital control, fuzzy neural network, intelligent control, adaptive control, and robotics.

Dr. Wang is currently serving as Associate Editor of IEEE TRANSACTIONS on Systems, MAN, AND Cybernetics, PART B: Cybernetics/ and as a Webmaster of IEEE Systems, Man, and Cybernetics Society.

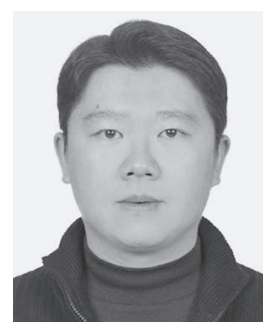

tronic technologies.
De-Yu Huang (M'10) was born in Taiwan, in 1976. He received the B.S. degree in electrical engineering from Tatung University, Taipei, Taiwan, in 1998, and received the M.S. degree in electrical control engineering from National Chiao Tung University, Hsinchu, Taiwan, in 2004. He is currently working toward the Ph.D. degree in electrical control engineering from National Chiao Tung University, Hsinchu, Taiwan.

His current research interests include intelligent control, fuzzy logic systems, and automobile elec- 